\title{
Inherently safer design and optimization of intensified separation processes for furfural production
}

DOI:

10.1021/acs.iecr.8b03646

\section{Document Version}

Accepted author manuscript

Link to publication record in Manchester Research Explorer

\section{Citation for published version (APA):}

Contreras-Zarazua, G., Sanchez-Ramirez, E., Vazquez-Castillo, J. A., Ponce-Ortega, J. M., Errico, M., Kiss, A., \& Segovia Hernandez, J. G. (2018). Inherently safer design and optimization of intensified separation processes for furfural production. Industrial \& Engineering Chemistry Research. https://doi.org/10.1021/acs.iecr.8b03646

\section{Published in:}

Industrial \& Engineering Chemistry Research

\section{Citing this paper}

Please note that where the full-text provided on Manchester Research Explorer is the Author Accepted Manuscript or Proof version this may differ from the final Published version. If citing, it is advised that you check and use the publisher's definitive version.

\section{General rights}

Copyright and moral rights for the publications made accessible in the Research Explorer are retained by the authors and/or other copyright owners and it is a condition of accessing publications that users recognise and abide by the legal requirements associated with these rights.

\section{Takedown policy}

If you believe that this document breaches copyright please refer to the University of Manchester's Takedown Procedures [http://man.ac.uk/04Y6Bo] or contact uml.scholarlycommunications@manchester.ac.uk providing relevant details, so we can investigate your claim.

\section{OPEN ACCESS}




\title{
1 Inherently safer design and optimization of intensified separation processes for furfural production
}

G. Contreras-Zarazúa, ${ }^{1}$ E. Sánchez-Ramírez, ${ }^{1}$ J. A. Vázquez-Castillo, ${ }^{2}$ J. M. Ponce-Ortega, ${ }^{3}$ M. Errico, ${ }^{4}$ A. A. Kiss, ${ }^{5,6}$ J. G. Segovia-Hernández ${ }^{1}$

${ }^{1}$ Deparment of Chemical Engineering University of Guanajuato, Noria Alta S/N, Guanajuato,Gto., 36000, Mexico.

${ }^{2}$ Faculty of Chemical Sciences, Autonomous University of Chihuahua, Circuito Universitario 8, Campus II, Chihuahua,Chih. 31125, Mexico

${ }^{3}$ Chemical Engineering Department, Universidad Michoacana de San Nicolás de Hidalgo, Morelia, Michoacán, 58060, México

${ }^{4}$ University of Southern Denmark, Department of Chemical Engineering, Biotechnology and Environmental Technology, Campusvej 55, DK-5230 Odense M, Denmark

${ }^{5}$ The University of Manchester, School of Chemical Engineering and Analytical Science, Centre for Process Integration, Sackville Street, The Mill, Manchester M13 9PL, United Kingdom, tony.kiss@manchester.ac.uk

${ }^{6}$ University of Twente, Sustainable Process Technology, PO Box 217, 7500 AE Enschede, The Netherlands

\begin{abstract}
Currently furfural production has increased the interest because of it is a bio-based chemical able to compete with fossil-based chemicals. Furfural is characterized by flammability, explosion and toxicity properties. Improper handling and process design can lead to catastrophic accidents. Hence it is of utmost importance to use inherent safety concepts during the design stage. This work is the first to present several new downstream separation processes for furfural purification, which are designed using an optimization approach that simultaneously considers safety criteria in addition to the total annual cost and the eco-indicator 99. The proposed schemes include: thermally coupled configuration, thermodynamic equivalent configuration, dividingwall column, and a heat integrated configuration. These are compared with the traditional separation process of furfural known as Quaker Oats Process. The results show that due to a large amount of water present in the feed, similar values are obtained for total annual cost and eco-indicator 99 in all cases. Moreover, the topology of the processes has an important role in the safety criteria, the thermodynamic equivalent configuration resulted as the safest alternative with a $40 \%$ of reduction of the inherent risk with respect to the Quaker Oats Process and thus it is the safest option to purify furfural.
\end{abstract}

Keywords: Furfural, Safer Process Design, Multi-Objective Optimization, Process Intensification, Bio-Refinery, inherent security.

\section{Introduction}

The development of chemicals from renewable resources as biomass attracted much research interest in the recent years, with a focus on novel renewable building blocks such as furfural. ${ }^{1}$ In fact, the U.S. Department of Energy compiled a list of Top 30 building block chemicals obtainable from biomass that could compete with chemical derived from the petroleum. Remarkably, furfural and two of its derivatives (furan dicarboxylic acid and levulinic acid) are highlighted in the top 10 in that list. ${ }^{2,3}$ Furfural has many industrial applications, being utilized as raw material for the production of other chemicals such as hexamethylenediamine (an intermediate compound used for the production of nylon 6-6) ${ }^{4}$ or phenol-furfural resins. ${ }^{5}$ Bhogeswararao and Srinivas ${ }^{6}$ proved that furfural can be converted to added-value chemicals such as furfuryl alcohol, tetrahydrofurfuryl alcohol, furan, tetrahydrofuran and diols, using conventional Pt and Pd catalyst and setting the appropriate reaction conditions and the support acidity. Due to its high affinity with molecules with double bonds, furfural is extensively used as an extractant. ${ }^{7}$ For example, Sun et al. ${ }^{8}$ and Cordeiro et al. ${ }^{9}$ have used furfural as solvent for the separation of benzene/cyclohexane mixture in an extractive dividing-wall column arrangement.

Furfural is usually produced from biomass rich in pentosane, e.g. sugar cane bagasse, corncobs, oat hulls, and sunflower husks among others. ${ }^{1,7}$ In 1922, the Quaker Oats Company created the first process to produce 
furfural at industrial scale using oat hulls as raw material, along with sulphuric acid and steam. ${ }^{7}$ This process has been characterized by easy implementation but a high purification cost and low conversions to furfural. The Quaker Oats process has not undergone great changes and it is now used to produce near $80 \%$ of the total world production of furfural. ${ }^{7,10}$

Up to now, most of the research work has focused on identifying cheap raw materials able to approach a sustainable and economic production of furfural. Blasi et al. ${ }^{11}$ discussed the pyrolytic behaviour of different hardwood and softwood biomasses with respect to the furfural yield. Mesa et al. ${ }^{12}$ presented a study where furfural is produced by diluted acid hydrolysis of sugarcane bagasse. De Jong and Marcotullio ${ }^{13}$ presented an overview of different technologies applied in various biorefineries where furfural is (co)produced. They also emphasize how diluted acid pre-treatment can be beneficial for large-scale applications. Additionally, Martin and Grossman ${ }^{14}$ have proposed a process for the coproduction of furfural and dimethyl furfural from algae and switchgrass. Moreover, they explored different pre-treatments technologies to improve the furfural conversion for many raw materials. Finally, Lui et $\mathrm{al}^{15}$, studied the possibility of taking advantage of hydrolysates of hardwoods to produce furfural.

However, there is a gap defining separation alternatives for product recovery leading to a strong interest in finding better downstream processing schemes in furfural production process. Typically, the solid biomass is treated with an acid solution at high temperature, and steam is used to maintain the reaction temperature and to remove the produced furfural obtained as a diluted aqueous stream. Similar to the separation of other bioderived compounds, such as bioethanol and biobutanol, the purification section represents one of the most energy-intensive parts of the process and process intensification and optimization techniques are required to come up with innovative and competitive production processes. ${ }^{16-19}$ Distillation is usually the first unit operation considered for separation at industrial level due to the high reliability reached in modelling, simulation, design and control, as well as the considerable amount of equilibrium data available. ${ }^{20}$ However, due to its low thermodynamic efficiency and high capital investment it is imperative to define enhanced configurations based on process intensification principles, ${ }^{21}$ not considered at the time when the original process was developed.

Qian et al. ${ }^{22}$ proposed an azeotropic divided wall column to separate a mixture of water-furfural. Using the traditional two-column azeotropic configuration as a benchmark, the azeotropic divided wall alternative proposed provided $3.8 \%$ savings in the total reboiler duty and proved the applicability of traditional proportional- integral controllers. However, the feed chosen by the authors contained $90 \%$ mole of furfural which does not match with typical bioprocesses. Nhien et al. ${ }^{10}$ proposed a hybrid process where furfural is recovered by liquid-liquid extraction. Many solvents were screened, but the best solution obtained was not compared against traditional distillation alternative and its convenience was not proved. As an alternative to distillation, the application of pervaporation has been also proposed. ${ }^{23}$

In this context, the definition of enhanced distillation configurations is of paramount importance in defining a furfural separation process integrated into a biorefinery. However, there are no previous studies that include safety criteria into the design of such process. Medina-Herrera et al. ${ }^{24,25}$ evaluated the inherent risk for distillation schemes with hydrocarbons mixtures and intensified extractives distillation schemes to recovery ethanol. Their results indicate that the amount of inventory in the columns and the physical properties of the substances have a strong impact on the inherent safety of the process. Martinez- Gomez et al. ${ }^{26}$ studied different intensified distillation processes to purify biobutanol and evaluated their individual risk - which is an index to evaluate the inherent safety - while considering economic and environmental criteria. Their results demonstrate that the process topology can influence the inherent safety. Additionally Martinez- Gomez et al. ${ }^{27}$ carried out a safety analysis of a process to produce silane by reaction distillation - one of the most popular examples of process intensification. Their results shows that process intensification can lead to important improvements in the safety aspects. Based on previous studies, it is evident that process intensification can be a powerful tool to improve not only the economical and energy aspects but also the process safety.

This study is the first to propose four intensified distillation sequences for furfural purification, and compare them with the separation section included in the Quaker Oats process. These separation processes were designed and optimized simultaneously considering a multi-objective function to analyze the process performance. The objective function combines the individual risk (IR) as quantification of the potential risk of the process, total 


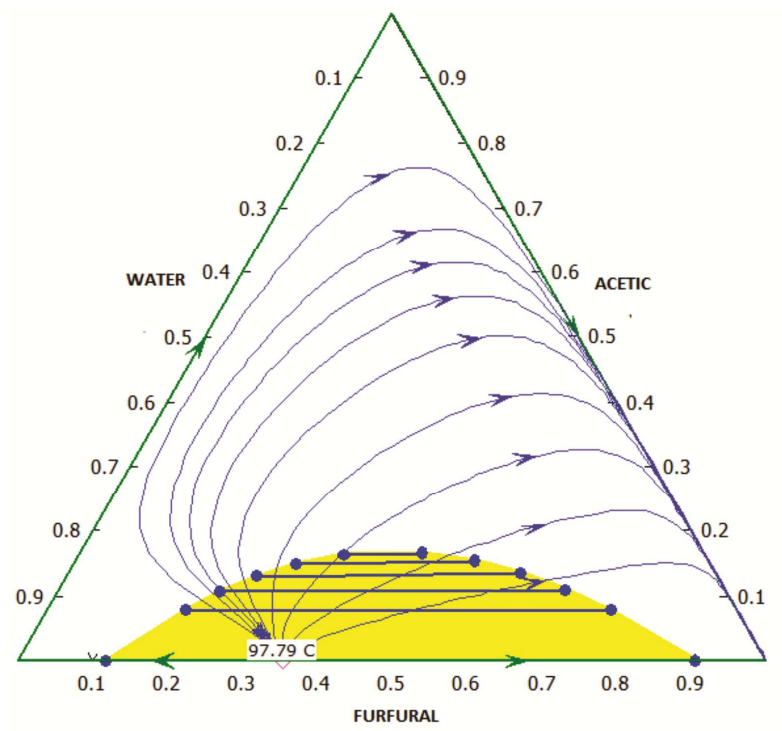

a)

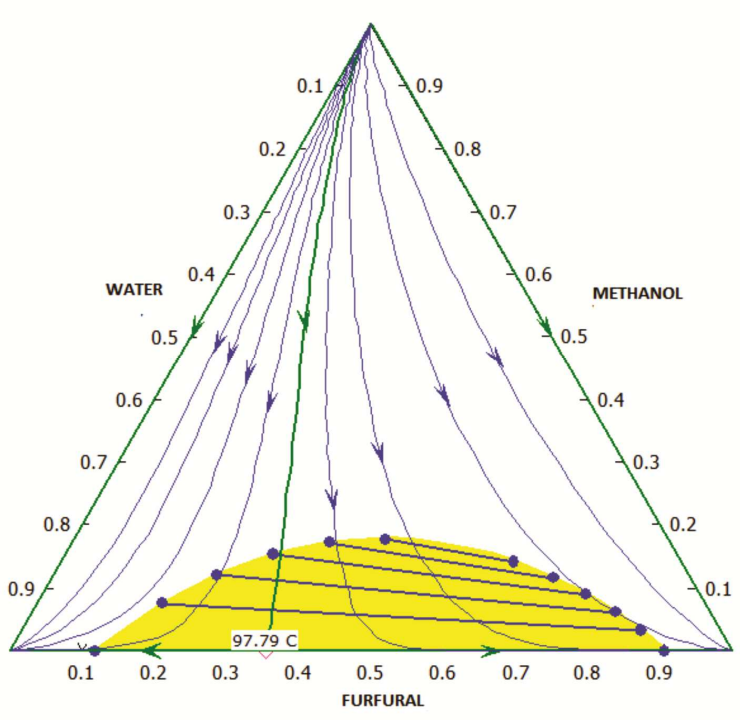

b)

Figure 1: Ternary diagrams for mixtures: a) water-furfural-acetic acid, b) water-furfural-methanol.

\section{Synthesis of the separation alternatives}

Figure 2 shows the classic furfural separation section considered as a benchmark. This configuration was developed according to the Quaker Oats process (QOP), reported in detail by Zeitsch ${ }^{7}$ and Nhien et al. ${ }^{10} \mathrm{~A}$ similar configuration was also examined by Steingaszner et al. ${ }^{32}$ The benchmark configuration consists of three distillation columns and a decanter for the liquid-liquid separation. The first column (C1) is commonly called 
azeotropic distillation column. Within C1 column, the mixture is concentrated until azeotrope composition. At this point, the water works as a very volatile components and dragging part of the furfural to the gas phase, which is condensate. After the condensation, two phases are formed and passed out to the decanter through the side stream. The phase enriched with water is returned to column $\mathrm{C} 1$ to promote the two liquids phases' formation. Furthermore, the water is removed for the bottom of $\mathrm{C} 1$ together with the acetic acid, avoiding its probably expensive purification. ${ }^{8}$ The methanol is recovered as distillate product of the second column (C2), while the bottom is fed to the decanter. The organic phase of decanter is fed to the column $\mathrm{C} 3$ used for the final step of furfural recovery. The distillate of the column C3 is sent back to the decanter, while the bottom stream is the furfural product.

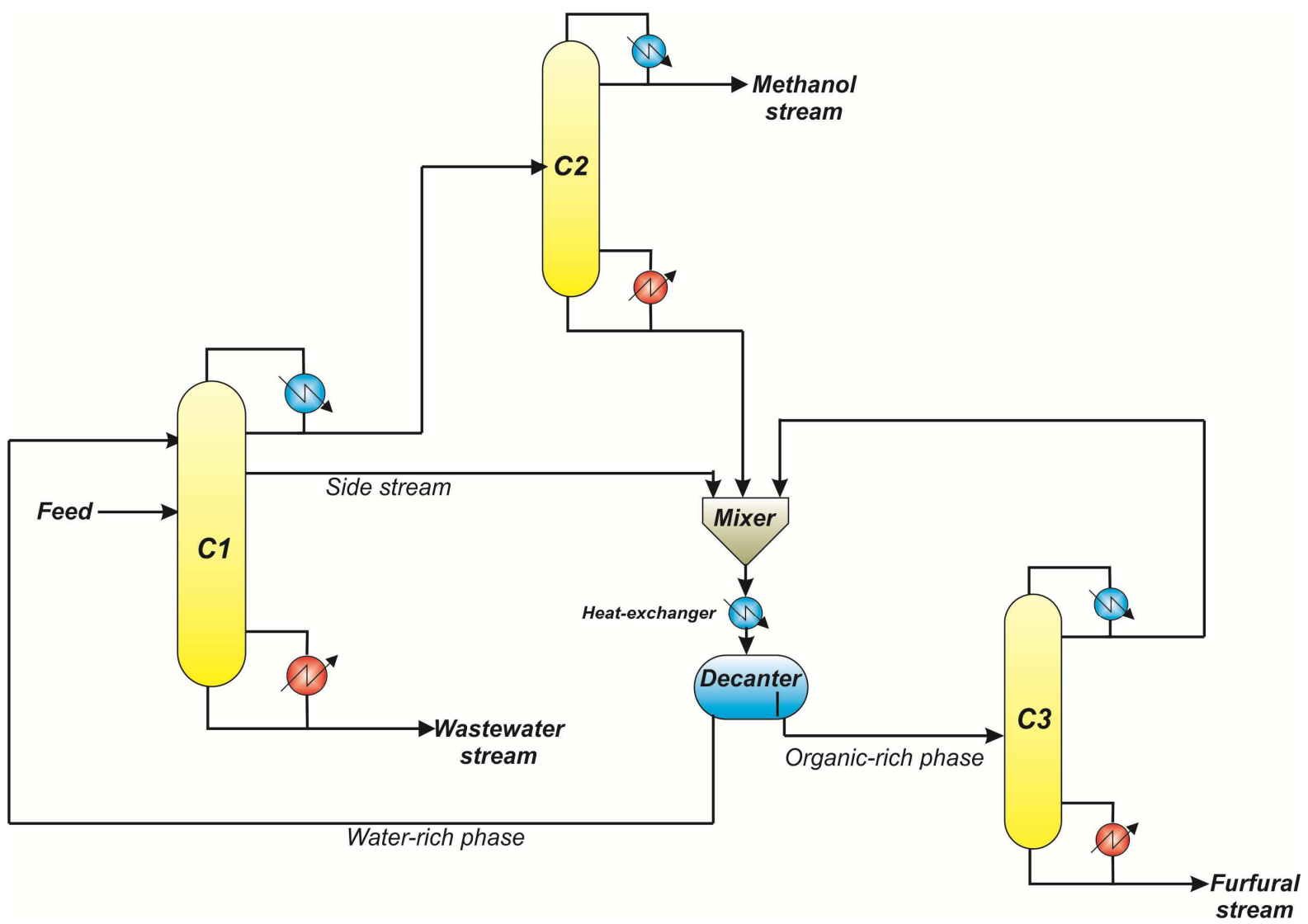

Figure 2: Benchmark configuration of the Quaker Oats process (QOP)

\subsection{Thermally coupled separation alternatives}

Thermally coupled configurations are obtained from the corresponding simple column sequences by substitution of a reboiler and / or a condenser not associated with product streams with a bidirectional liquid and vapor stream. The effect of the thermal coupling is related to the decrease of thermodynamic inefficiencies generated by the remixing of components. It was extensively proved that in many cases, thermally coupled configurations are more energy efficient as compared to simple column sequences. ${ }^{33-35}$ Starting from the reference configuration shown in Figure 2, it is possible to generate the thermally coupled arrangement, in this way the column is divided in sections, according to Hohmann et al. ${ }^{36}$ a column section is commonly defined as a portion of distillation column not interrupted by entering or existing streams or heat flows. These sections are illustrated in Figure 3 with roman numerals. In the case of thermally coupled configuration (TCC) showed in Figure 3 (a), the condenser associated to the first column was substituted by vapour and liquid streams which are linked in the last and penultimate stages of section IV respectively, this arrangement is commonly called thermal coupling. The introduction of this thermal coupling provides a flexibility to generate new designs, because the 
1 thermal coupling allows to move the sections between columns from a conceptual point of view. The 2 corresponding thermodynamic equivalent configuration (TEC) is generated moving the section IV of the column 3 C2 upon rectifying section I of column $\mathrm{C} 1$ as it is illustrated in Figure 3 (b). In general, for thermodynamic 4 equivalent configurations, a better liquid and vapor flow rate redistribution among the column sections is 5 expected together with a better controllability ${ }^{37,38}$. For this reason, the TEC was considered as a possible 6 alternative to the classic separation scheme.

7

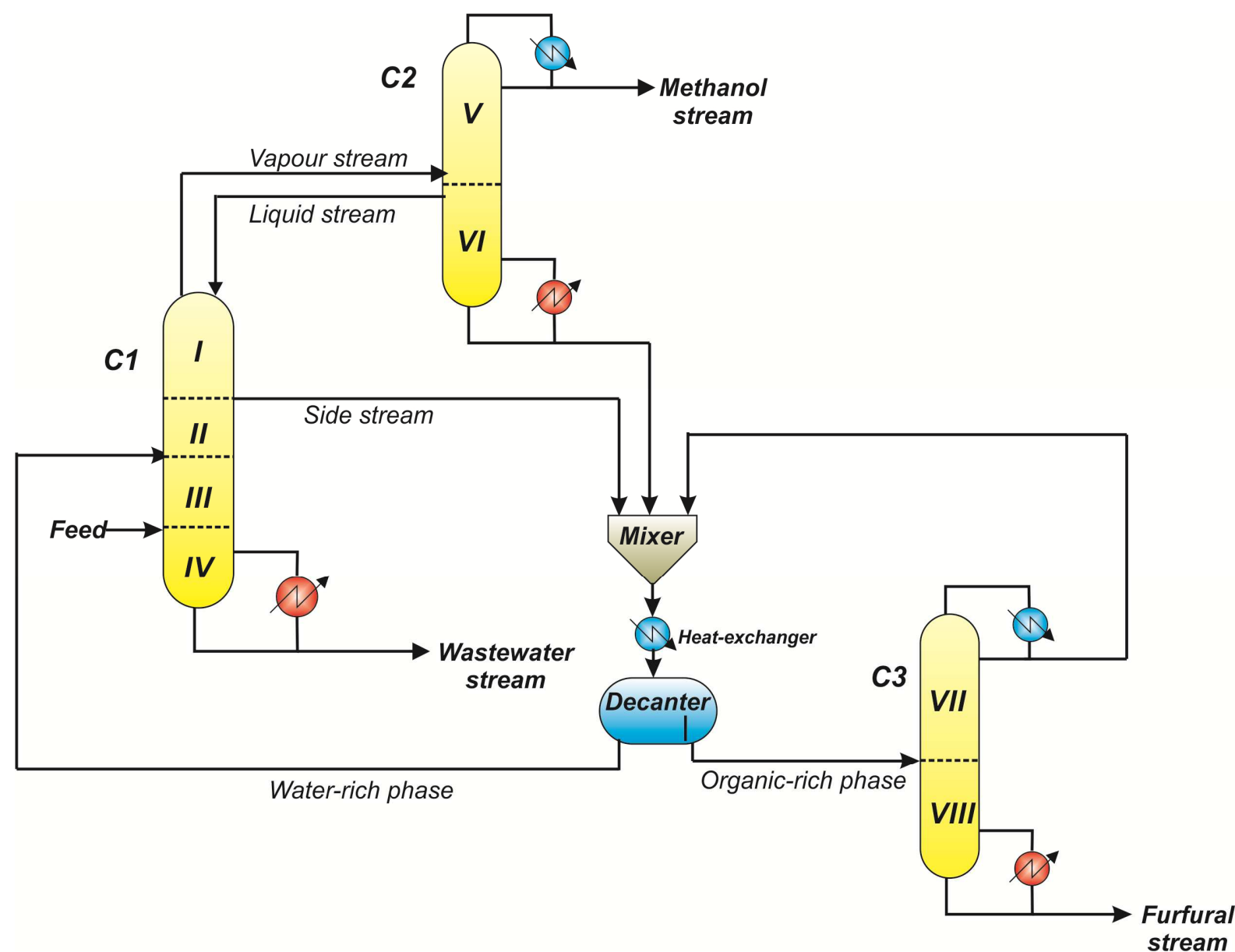




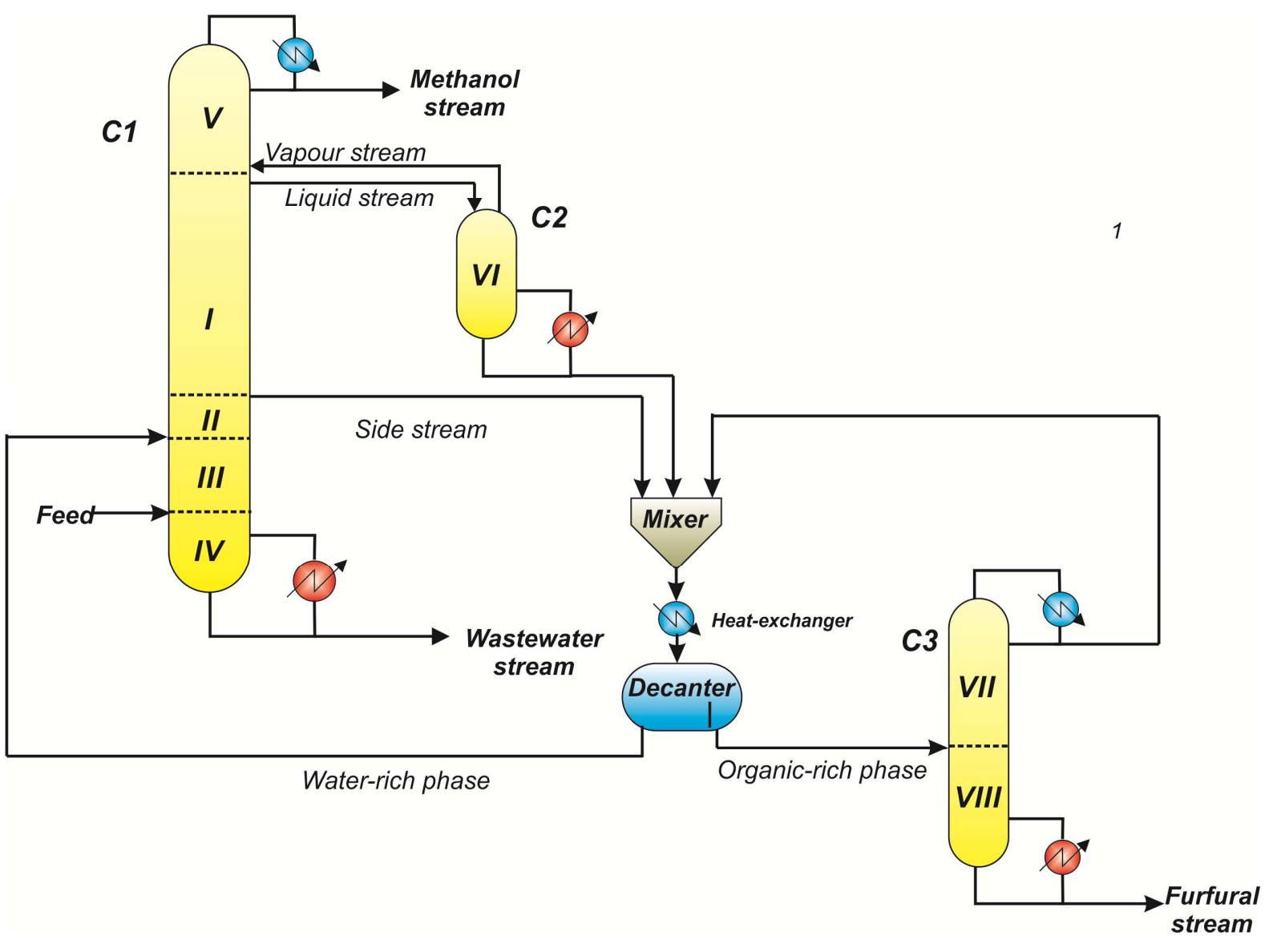

b)

3 Figure 3: a) Thermally coupled configuration (TCC); b) Thermodynamic equivalent configuration (TEC).

\subsection{Dividing-wall column configuration}

Dividing-wall columns are considered as a leading example of process intensification applied to multicomponent distillation. It is an attractive alternative since it has the potential for reducing the operating and capital cost. Previous works explored among others their design, controllability and possible applications to the separation of biofuels. ${ }^{39-44}$ The divided wall column configuration (DWCC) considered for the furfural separation is shown in Figure 4. It was obtained merging column $\mathrm{C} 1$ and $\mathrm{C} 2$ in a single shell divided by an internal wall. From a conceptual point of view the length of the wall is determinate by the number trays of the sections of columns $\mathrm{C}$. The wall is extended to the column bottom in order to separate two bottom streams. For this reason, the DWCC unit is equipped with two reboilers. However, only one distillate product is obtained. 


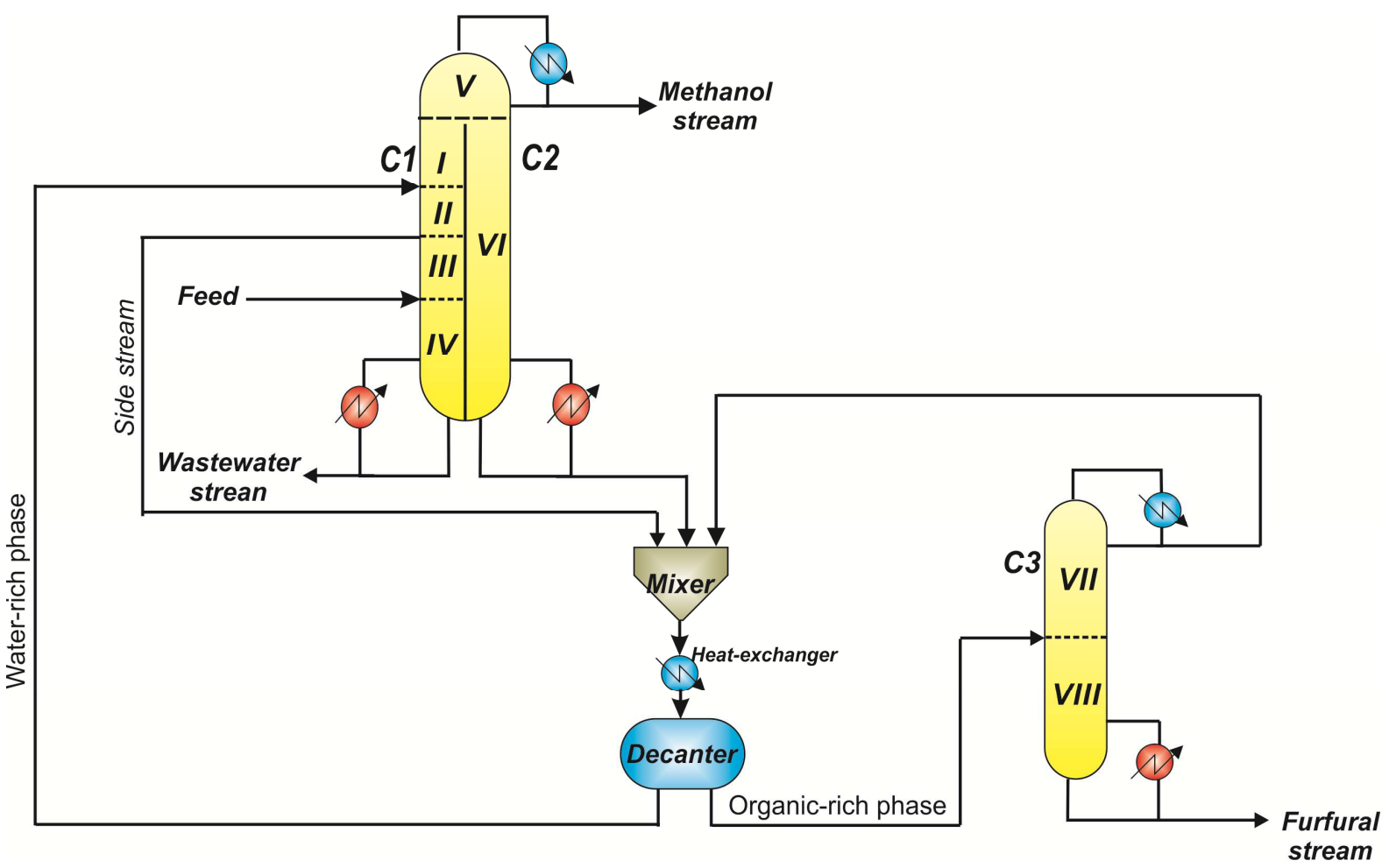

2 Figure 4: Dividing-wall column configuration (DWCC)

\subsection{Heat integrated configuration}

The main principle behind heat integration in distillation configurations is to use the energy sources or sinks available in other process streams to condense the vapor in the overhead of a column, or to provide the reboiler duty required. As reported by Rathore et al. ${ }^{45}$ the process streams might be the reboiler or condenser streams in the same separation sequence. Heat integrated alternatives were deeply explored in the literature and they still represent a valid alternative to reduce the energy requirements of multi-component distillation ${ }^{45-51}$. The heat integrated configuration (HIC) considered in this work is illustrated in Figure 5. The selected heat integration strategy for the heat integrated configuration (HIC) consist on the utilization of the latent heat of the vapour stream leaving the top part of the column C3, the temperature of this stream is increased through the use of a compressor, the main target in this configuration with heat integration is to upgrade and reuse the heat of the vapor stream to mitigate the duty in the reboiler of $\mathrm{C} 2$ and to condensate the vapour. After condensation, it is partially recycled to the column $\mathrm{C} 3$ to ensure the liquid reflux. The function of the compressor is to increase the temperature of the vapour stream in order to guarantee that its temperature is higher than the temperature of the bottom of the column 2 . The heat integration can causes important energy savings in the process. This strategy has gained attention in recent years and it has been proven to achieve an efficient way the heat integration in separation processes, for instance see the works by Jana \& Maiti ${ }^{48}$; Luo et al ${ }^{49}$; Contreras Zarazúa et al. ${ }^{50}$ and Zang et al. ${ }^{51}$. 


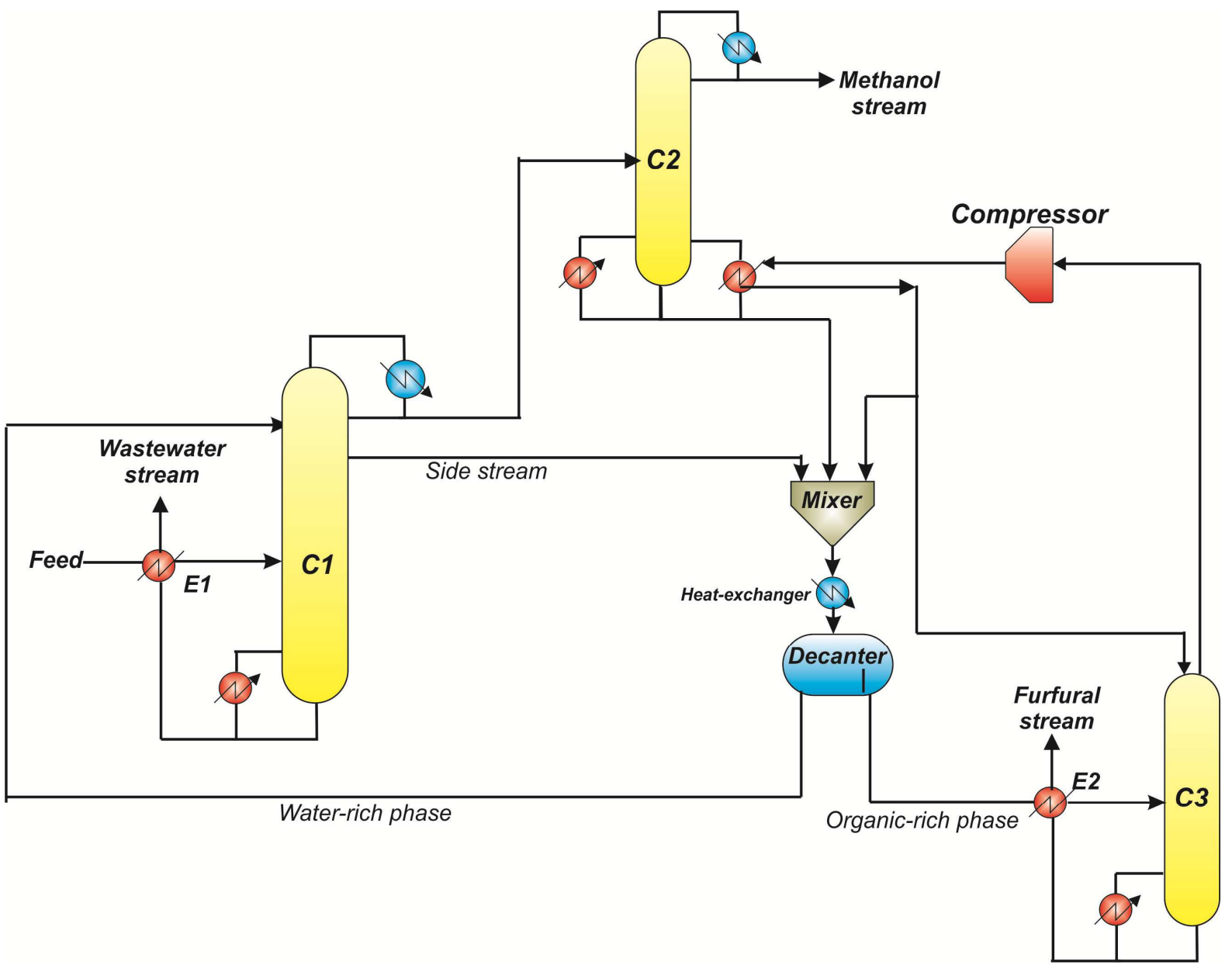

2 Figure 5: Heat integrated configuration (HIC)

\section{Objective function definition}

The objective function is constructed by combining three different and contrasting indexes representing the economy (total annual cost), the environmental impact (eco-indicator 99), and the process safety (individual risk). Each index is described in the following subsections.

\subsection{Plant economy: Total annual cost (TAC)}

TAC is the classical approach used to quantify the economic performance of a chemical process alternative. The methodology consists in calculating the annualized cost of each processes equipment (capital cost) and the operating cost associated with the use of steam, cooling water and electricity. The equation for TAC is given by:

$$
\mathrm{TAC}=\frac{\text { Capital cost }}{\text { Payback period }}+\text { Operating cost }
$$

The capital cost includes the cost of condensers, reboilers, distillation columns, trays, process vessels and compressors, whereas the operating cost is associated with the cost of steam, cooling water and electricity. The TAC was calculated using the Guthrie method. ${ }^{52}$ Carbon steel was considered as construction material. A payback period of ten years was used. Sieve trays and $0.61 \mathrm{~m}$ spacing were selected for all the columns. All the parameters for the equipment and the utility costs were taken from Turton et al. ${ }^{53}$ Five utility cost have been considered: high-pressure steam (42 bar, $\left.254{ }^{\circ} \mathrm{C}, \$ 17.7 / \mathrm{GJ}\right)$, medium-pressure steam (11 bar, $184{ }^{\circ} \mathrm{C}$, $\$ 14.83 / \mathrm{GJ})$, low-pressure steam (6 bar, $\left.160{ }^{\circ} \mathrm{C}, \$ 14.95 / \mathrm{GJ}\right)$, cooling water $(\$ 0.72 / \mathrm{GJ})$, and electricity $(\$ 16.8 / \mathrm{GJ})$. The operating costs were evaluated considering 8500 hours of yearly operation.

\subsection{Environmental impact: Eco-Indicator 99 (EI99)}


The Eco-Indicator 99 was used to evaluate the sustainability of the processes and to quantify the environmental impact due to the multiple activities performed in the process. This methodology is based on the life cycle assessment. The approach was proposed by Goedkoop and Spriensma. ${ }^{54}$ The EI99 has proven to be an important method to evaluate overall environmental impact related in chemical processes. Some authors - such as GuillenGonzalvez et. al., ${ }^{55}$ Alexander et al. ${ }^{56}$ and Quiroz-Ramirez et al. ${ }^{57}$ - have demonstrated that applying the ecoindicator 99 during the design and synthesis phases can lead to important improvements and reductions of wastes. The index was applied successfully in screening different alternatives for biofuels purification giving as results the optimal configuration with the lowest environmental impact and cost. ${ }^{19,30}$

The method is based on the evaluation of three major damage categories: human health, ecosystem quality, and resources depletion. In case of distillation columns, the factors that have the strongest influence on EI99 are the steam used to supply the heat duty, electricity utilized for pumping of cooling water, and the steel necessary to build the equipment. ${ }^{19,30}$ The eco-indicator 99 can be represented mathematically according to Eq. 2 as follows:

$$
E I 99=\sum_{i} \omega \cdot c_{i} \cdot a s+\sum_{i} \omega \cdot c_{i} \cdot a s l+\sum_{i} \omega \cdot c_{i} \cdot a e
$$

where $\omega$ is a weighting factor for damage, $c_{i}$ is the value of impact for category $\mathrm{i}$, as is the amount of steam utilized by the process, asl is the amount of steel used to build the equipment, ael is the electricity required by the process . For example, the amount of steam used to provide energy to plant is multiplied by the damage impact of each category, and subsequently the summation of all the products is performed to obtain the ecoindicator due to steam, the procedure is the same for steel and electricity. For the weighting factor $\omega \mathrm{d}$, we have followed the method of eco-indicator 99, separating the impact categories as damages to the human health (expressed in disability adjusted life years "DALYs"), damage to the ecosystem quality (expressed as the loss of species over a certain area $\%$ species $\mathrm{m} 2 \mathrm{yr}$ ), and damage to resources (expressed as the surplus energy needed for future extractions of minerals and fossil fuels, "MJ surplus"). The damage to the human health and to the ecosystem quality are considered to be equally important, whereas the damage to the resources is considered to be about half as important. Furthermore, in the presented approach the hierarchical perspective was considered to balance the short- and the long-term effects. The normalization set is based on a damage calculation for all relevant emissions, extractions and land-uses ${ }^{58}$. The values presented in Table 1 represent $\alpha_{\mathrm{bk}}$, the damage caused in category $k$ per unit of chemical $b$

Finally, the total EI99 is obtained by the summation of eco-indicator due to steam, electricity and steel. For compute the EI99, a hierarchical perspective is considered for the evaluation of environmental impact in order to have a balance between short- and long-term effects. ${ }^{54,57}$ Table 1 shows the impact categories and values used in this study. These values were taken from the work reported by Geodkoop and Spriensma ${ }^{54}$ these values are associated and corresponding with the use of steel for building the equipment and with the use of energy utilized during the plant operation, two factor that are independent of the type of process .

Table 1. Values of EI99 impact categories used for distillation columns. ${ }^{54}$

\begin{tabular}{llll}
\hline Impact category & Steel $\left(\right.$ points/kg) $\times \mathbf{1 0}^{-3}$ & Steam $($ points/kg) & Electricity (points/kWh) \\
\hline Carcinogenic & $1.29 \times 10^{-3}$ & $1.180 \times 10^{-4}$ & $4.360 \times 10^{-4}$ \\
Climate change & $1.31 \times 10^{-2}$ & $1.27 \times 10^{-3}$ & $4.07 \times 10^{-3}$ \\
Ionizing radiation & $4.510 \times 10^{-4}$ & $1.91 \times 10^{-6}$ & $8.94 \times 10^{-5}$ \\
Ozone depletion & $4.550 \times 10^{-6}$ & $7.78 \times 10^{-7}$ & $5.41 \times 10^{-7}$ \\
Respiratory effects & $8.010 \times 10^{-2}$ & $1.56 \times 10^{-3}$ & $1.01 \times 10^{-5}$ \\
Acidification & $2.710 \times 10^{-3}$ & $1.21 \times 10^{-4}$ & $9.88 \times 10^{-4}$ \\
Ecotoxicity & $7.450 \times 10^{-2}$ & $2.85 \times 10^{-4}$ & $2.14 \times 10^{-4}$ \\
Land occupation & $3.730 \times 10^{-3}$ & $8.60 \times 10^{-5}$ & $4.64 \times 10^{-4}$ \\
Fossil fuels & $5.930 \times 10^{-2}$ & $1.24 \times 10^{-2}$ & $1.01 \times 10^{-2}$
\end{tabular}




$$
\text { Mineral extraction } \quad 7.420 \times 10-2 \quad 8.87 \times 10^{-6} \quad 5.85 \times 10^{-5}
$$

The scale of the values considered in Table 1 is chosen such that the value of 1 point is representative for a 1000th of the yearly environmental load of one average European inhabitant. ${ }^{30,54-55}$

\subsection{Process safety: Individual risk (IR)}

The individual risk (IR) was used as index to evaluate the safety. The IR can be defined as the risk of injury or decease to a person in the vicinity of a hazard. ${ }^{59}$ The main objective of this index is the estimation of likelihood affectation caused by the specific incident that occurs with a certain frequency. The IR does not depend on the number of people exposed. The mathematical expression for calculating the individual risk is the following:

$$
I R=\sum f_{i} P_{x, y}
$$

Where $f_{i}$ is the occurrence frequency of incident $i$, whereas $P_{x, y}$ is the probability of injury or decease caused by the incident $i$. In this work, an irreversible injury (decease) is used, for which more data are recorded. The calculation of IR can be carried out through quantitative risk analysis (QRA), which is a methodology used to identify incidents and accidents and their consequences. The QRA starts with the identification of possible incidents. For distillation columns are identified two types of incidents: continuous and instantaneous releases. A continuous release is produced mainly by a rupture in a pipeline or partial rupture on process vessel causing a leak. The instantaneous release consists in the total loss of matter from the process equipment originated by a catastrophic rupture of the vessel. These incidents were determined through hazard and operability study (HAZOP). The procedure is effective in identifying hazards and it is well accepted by the chemical industry. The technique consists in to systematically analyse the reasons and consequences that can provoke deviations in the operative conditions of process that can derivate in an accident through a series of questions such as: how?, where?, when?, etc. More information about this technique is provide by $\mathrm{AIChE}^{59}$ and Crowl and Louvar ${ }^{60}$. The frequencies values for each incident $\left(f_{i}\right)$ were taken according to the reported by American Institute of Chemical Engineers (AIChE) ${ }^{59}$ Figure 6 shows the event tree diagrams obtained with all probabilities of instantaneous and continuous incidents, along with their respective frequencies. Accordingly, instantaneous incidents are: boiling liquid expanding vapor explosion (BLEVE), unconfined vapor cloud explosion (UVCE), flash fire and toxic release, whereas the continuous release incidents are: jet fire, flash fire and toxic release. The complete set of equations to calculate the IR is shown in the Eqs.S1-S8 of the supplementary material and more information about these equations is given by $\mathrm{AIChE}^{59}$ and Crowl and Louvar ${ }^{60}$.

Once the incidents have been identified, the probability $P_{x, y}$ can be calculated through a consequence assessment, which consists in determining the physical variables as the thermal radiation, the overpressure and the concentration of the leak originated by incidents, and their respective damages. The calculation of the physical variables was realized according to the equations reported by the $\mathrm{AIChE}^{59}$ and some other authors such as Medina-Herrera et al. ${ }^{24,25}$ The atmospheric stability type $\mathrm{F}$ is used for calculating the dispersion, which corresponds to a wind speed of $1.5 \mathrm{~m} / \mathrm{s}$. This atmospheric condition is the worst possible scenario due to the low wind speed does not allow a fast dispersion of flammable and toxic components, increasing the time of exposure and the probability to get in contact with an ignition source ${ }^{59,60}$.

The quantification of the damage caused by physical variables of each incident is calculated through a vulnerability model commonly known as probit model ${ }^{59,60}$. In this work, the damage considered to people is death due to fires, explosions and toxic releases, all calculations were carried out to a representative distance of $50 \mathrm{~m}$. The probit models associated with deaths by thermal radiation $\left(t_{e} E_{r}\right)$ and overpressure due to explosions $\left(p^{\circ}\right)$ are given by Eq.4 and Eq. $5^{59}$ :

$$
Y=-14.9+2.56 \ln \left(\frac{t_{e} E_{r}^{\frac{4}{3}}}{10^{4}}\right)
$$




$$
Y=-77.1+6.91 \ln \left(p^{\circ}\right)
$$

Due to there are not reported toxicity probit models for components considered in this work, the calculation of the damage to toxic releases were carried out using the LC50 59 more information about this calculate is provide in the supplementary material. Finally, the probability $P_{x, y}$ is calculated substituting the probit results of the Eq.4 and Eq.5 into the following equation:

$$
P_{x, y}=0.5\left[1+\operatorname{erf}\left(\frac{Y-5}{\sqrt{2}}\right)\right]
$$

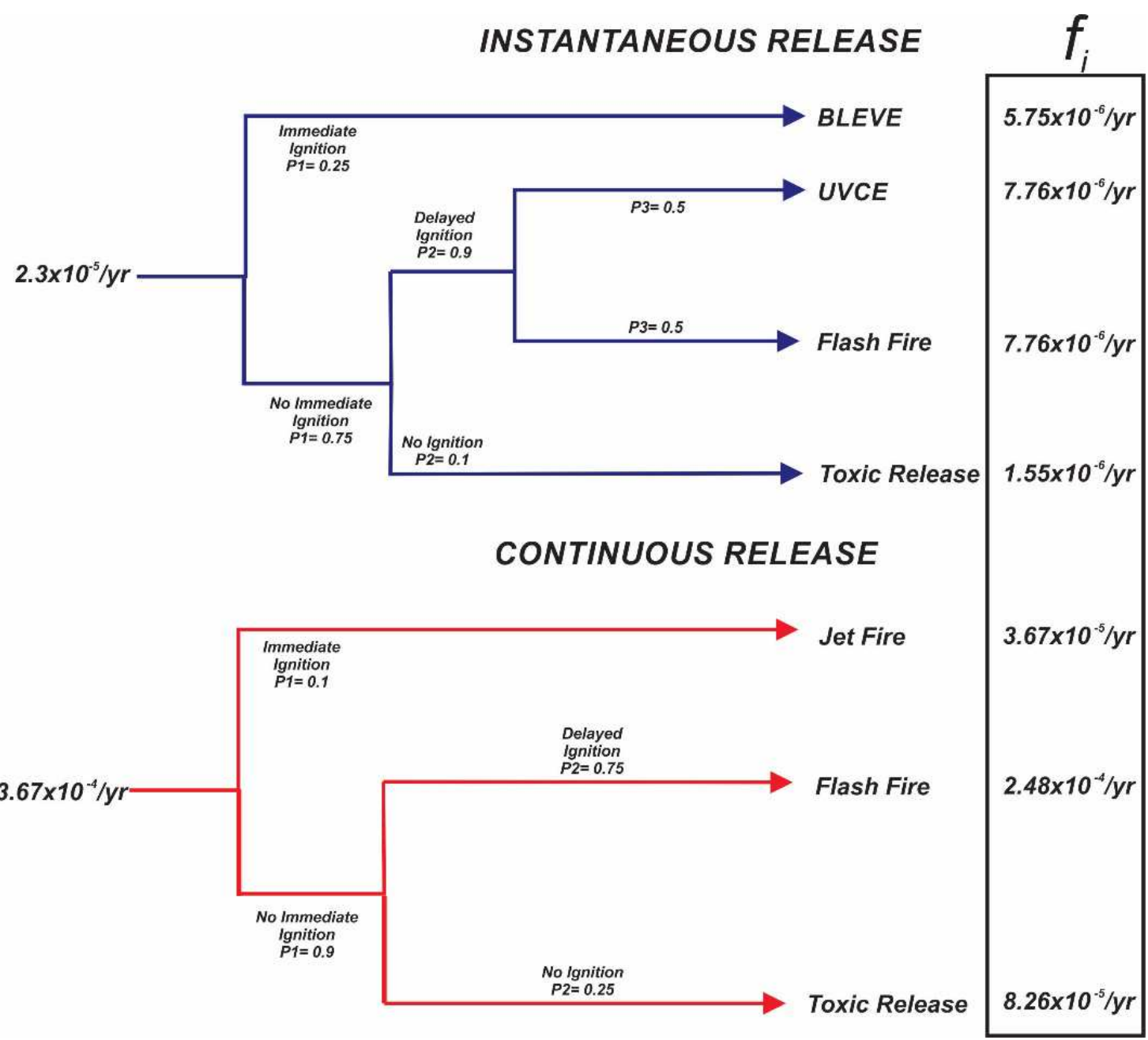

Figure 6: Event tree diagrams for distillation schemes ${ }^{59,24}$

The physical properties for each substance used for the consequence assessment are reported in Table 2. These were taken from the National Institute for Occupational Safety and Health (NIOSH). ${ }^{61}$

Table 2. Physical properties of components

\begin{tabular}{lcccc}
\hline Component & $\begin{array}{c}\text { Lower } \\
\text { flammability } \\
\text { limit (LFL) }\end{array}$ & $\begin{array}{c}\text { Upper } \\
\text { flammability } \\
\text { limit (UFL) }\end{array}$ & $\begin{array}{c}\text { Lethal } \\
\text { concentration } \\
\text { (LC50) }\end{array}$ & $\begin{array}{c}\text { Heat } \\
\text { Combustion } \\
(\mathbf{k J} / \mathbf{m o l})\end{array}$ \\
\hline Furfural & 2 & 19 & $64,000 \mathrm{ppm} / 4 \mathrm{~h}$ & 2344 \\
Methanol & 6 & 36 & $1037 \mathrm{ppm} / 1 \mathrm{~h}$ & 726
\end{tabular}




$\begin{array}{lllll}\text { Acetic Acid } & 6 & 17 & 16000 \mathrm{ppm} / 4 \mathrm{~h} & 876.1\end{array}$

\subsection{Multi-objective optimization problem formulation}

Once the economic, environmental and safety indexes have been described, the mathematical optimization problem considering all indexes can be expressed according to:

$$
\min [T A C, E I 99, I R]=f\left(N T_{i}, F s_{i}, R_{i}, V F, L F, D C_{i}, H D_{i}, k, C_{i, j}\right)
$$

Subject to:

$$
\begin{aligned}
& \overrightarrow{y_{m}} \geq \overrightarrow{x_{m}} \\
& \overrightarrow{w_{m}} \geq \overrightarrow{u_{m}}
\end{aligned}
$$

where $N T_{i}$ represents the total number of stages of column i, $F s_{i}$ is the feed stages for column i, $R_{i}$ is the reflux ratio of column $\mathrm{i}, V F$ is the interconnection vapour flow, $L F$ is the interconnection liquid flow, $D C_{i}$ is the diameter of column i, $H D_{i}$ is the reboiler duty for column i, $k$ is the compressor capacity, $C_{i, j}$ in the concentration of substance $\mathrm{j}$ in column $\mathrm{i}$. The optimization problem is restricted to satisfy the constraint vectors of purity and mass flowrate for interest substances in the mixture. In this work $y_{m}$ and $w_{m}$ are the vectors of obtained purity and mass flowrate, while $u_{m}$ and $x_{m}$ are the vectors of required purity and mass flowrate, respectively. The purity constraints for methanol and furfural were defined as $99.5 \%$ and $99.2 \%$ mass fraction, whereas the mass flow rate was set at $2000 \mathrm{~kg} / \mathrm{h}$ for methanol and $6200 \mathrm{~kg} / \mathrm{h}$ for furfural in the methanol and furfural streams respectively. Note that the Eq.7 is a general equation for all sequences, some terms like interconnection flows, capacity of compressor or heat duty for a specific column could be discarded depending on the studied scheme. Table 3 shows detailed information about the decision variables considered for each of the separation schemes. The ranges of decision variables are reported in the Table S2 of supplementary material. The ranges for the

\begin{tabular}{|c|c|c|c|c|c|}
\hline Decision Variables & QOP & TCC & TEC & DWCC & HIC \\
\hline \multicolumn{6}{|c|}{ Discrete Variables } \\
\hline Number of stages, C1 & $\mathrm{X}$ & $\mathrm{X}$ & $\mathrm{X}$ & $\mathrm{X}$ & $\mathrm{X}$ \\
\hline Number of stages, C2 & $\mathrm{X}$ & $\mathrm{X}$ & $X$ & $\mathrm{X}$ & $\mathrm{X}$ \\
\hline Number of stages, C3 & $X$ & $\mathrm{X}$ & $X$ & $\mathrm{X}$ & $\mathrm{X}$ \\
\hline Feed stage recycle of $\mathrm{C} 1$ & $\mathrm{X}$ & $\mathrm{X}$ & $\mathrm{X}$ & $X$ & $X$ \\
\hline Feed stage, $\mathrm{C} 1$ & $\mathrm{X}$ & $\mathrm{X}$ & $X$ & $\mathrm{X}$ & $\mathrm{X}$ \\
\hline Stage of side stream C1 & $\mathrm{X}$ & $\mathrm{X}$ & $X$ & $X$ & $\mathrm{X}$ \\
\hline Feed stage $\mathrm{C} 2$ & $X$ & $\mathrm{X}$ & $X$ & $X$ & $\mathrm{X}$ \\
\hline Feed stage C3 & $\mathrm{X}$ & $\mathrm{X}$ & $\mathrm{X}$ & $\mathrm{X}$ & $\mathrm{X}$ \\
\hline \multicolumn{6}{|c|}{ Continuous Variables } \\
\hline Mass flow side stream $\mathrm{C} 1$ & $X$ & $\mathrm{X}$ & $\mathrm{X}$ & $X$ & $\mathrm{X}$ \\
\hline Reflux ratio of $\mathrm{C} 1$ & $\mathrm{X}$ & - & $X$ & - & $\mathrm{X}$ \\
\hline Reflux ratio of $\mathrm{C} 2$ & $\mathrm{X}$ & $\mathrm{X}$ & - & $X$ & $\mathrm{X}$ \\
\hline Reflux ratio of C2 & $\mathrm{X}$ & $\mathrm{X}$ & $X$ & $X$ & $X$ \\
\hline Heat duty of $\mathrm{C} 1, \mathrm{~kW}$ & $\mathrm{X}$ & $\mathrm{X}$ & $\mathrm{X}$ & $\mathrm{X}$ & $\mathrm{X}$ \\
\hline Heat duty of $\mathrm{C} 2, \mathrm{~kW}$ & $\mathrm{X}$ & $X$ & $X$ & $X$ & $\mathrm{X}$ \\
\hline Heat duty of $\mathrm{C} 3, \mathrm{~kW}$ & $\mathrm{X}$ & $\mathrm{X}$ & $\mathrm{X}$ & $\mathrm{X}$ & $\mathrm{X}$ \\
\hline Diameter of $\mathrm{C} 1, \mathrm{~m}$ & $\mathrm{X}$ & $\mathrm{X}$ & $X$ & $X$ & $\mathrm{X}$ \\
\hline Diameter of $\mathrm{C} 2, \mathrm{~m}$ & $\mathrm{X}$ & $\mathrm{X}$ & $\mathrm{X}$ & $\mathrm{X}$ & $\mathrm{X}$ \\
\hline Diameter of C3, m & $\mathrm{X}$ & $X$ & $\mathrm{X}$ & $\mathrm{X}$ & $\mathrm{X}$ \\
\hline $\begin{array}{l}\text { Discharge pressure of } \\
\text { compressor }\end{array}$ & - & - & - & - & $\mathrm{X}$ \\
\hline
\end{tabular}
designs variables are within the limits reported by Gorak and Olujic ${ }^{62}$.

Table 3. Decision variables of the separation process configurations 
Interlinking flow

Heat integrated E1, kW

Heat integrated E2, kW

Total number of variables

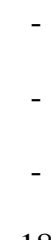

18
$\mathrm{X}$

18
$\mathrm{X}$

18
X

$\mathrm{X}$

$\mathrm{X}$

\subsection{Multi-objective optimization strategy}

This study uses a multi-objective optimization technique known as Differential Evolution with Tabu List (DETL) proposed by Srinivas and Rangaiah ${ }^{63}$ which is a stochastic global optimization technique. The DETL algorithm combines two very useful optimization techniques, the differential evolution (DE) and Tabu search (TS). The differential evolution method is a population-based direct search method that imitates the biological evolution - it was designed to solve optimization problems with nonlinear and non-differentiable equations. ${ }^{64}$ The Tabu search is a random search method that has the ability to remember the search spaces previously visited. ${ }^{63}$ The main advantages provided by DE is its faster convergence to the neighborhood global optimum in comparison to other stochastic methods, this algorithm has the capacity to escape from local due to its nature to be a method of global search. The main characteristic of TS is avoiding re-visiting the search space through the introduction of a so called taboo list, leading to a reduction in the computational time. ${ }^{63}$ The advantage of combining the DE with taboo list concept is a faster convergence to vicinity of global optima compared with a single differential evolution method and less computational time and effort. ${ }^{63,65}$ The implementation of the DETL method is carried out in a hybrid platform, which involves a link between Microsoft Excel ${ }^{\mathrm{TM}}$ and the process simulator Aspen Plus ${ }^{\mathrm{TM}}$, where the optimization algorithm is programmed in Excel through a Visual Basic macro, whereas Aspen Plus is used to rigorously simulate the process. In general terms, all modules in the flowsheets of the cases of study were solved in Aspen by means of solving the entire set of MESH (material balances, equilibrium relationships, summation equations and heat (enthalpy) balances). The DETL algorithm consists mainly of four steps which are: initialization, mutation, crossover, evaluation -selection ${ }^{63,66}$. In general these steps are described as follows:

Initialization. In the initialization step the algorithm search in a D-dimensional space $\Re^{D}$, where different vectors are generate randomly in a certain limited range of values (in this cases feasible diameters, reflux, trays of columns, etc) for each different generation G. All these vectors are possible solutions for the optimization problem and can be represented according to Eq. (8).

$$
\overrightarrow{X_{i, G}}=\left[X_{1, G}, X_{i, G}, X_{i, G}, \ldots, X_{i, G}\right]
$$

Mutation: The mutation step can be described as a change or disturbance occasioned by a random element $(F)$. Starting from a parent vector (named target vector), this parent vector is further muted to generate a donor vector. Finally, the mutant vector is obtained recombining both the donor and target vector. We can write the process as Eq. (9)

$$
\overrightarrow{V_{i, G}}=\overrightarrow{X_{r_{1, G}^{i}}}+F\left(\overrightarrow{X_{r_{2, G}^{i}}}-\overrightarrow{X_{r_{3, G}^{i}}}\right)
$$

Where $\overrightarrow{V_{i, G}}$ is the mutant vector, $\overrightarrow{X_{r_{1, G}^{i}}}$ is the parent vector, $\overrightarrow{X_{r_{2, G}^{i}}}$ and $\overrightarrow{X_{r_{3, G}^{i}}}$ are randomly vectors selected from the current generation, and $F$ is the mutation factor.

Crossover: Following with the crossover step, the mutant vector exchanges its components with the target vector under this operation to form the trial vector $\overrightarrow{U_{i, G}}=\left[u_{1, i G}, u_{2, i G}, u_{3, i G}, \ldots, u_{D, i G}\right]$.The cross is controlled by probability factor $(\mathrm{Cr})$ which has values between 0 and 1 . Each $u_{j, i G}$ values of trial vector is generated by a randomly selection of values from mutant vector and parent vector according with Eq. 10. 


$$
u_{j, i, G}=\left\{\begin{array}{l}
v_{j, i, G} \text { if }\left(\operatorname{rand}_{i, j}[0,1]\right) \leq C r \\
x_{j, i, G} \text { otherwise }
\end{array}\right.
$$

2

Where $\operatorname{rand}_{i, j}[0,1]$ is aleatory number, $v_{j, i, G}$ and $x_{j, i, G}$ are elements from the mutant and parent vector respectively.

Selection: Finally evaluation-selection step is carry out to keep the population size as a constant number, the selection step determine if the target or the trial vector survives from the generation $G$ to the next generation $G+1$. The selection operation is described as follows in Eq.11.

$$
\begin{array}{ll}
\overrightarrow{X_{i, G+1}}=\overrightarrow{U_{i, G}} & \text { if } f\left(\overrightarrow{U_{i, G}}\right) \leq f\left(\overrightarrow{X_{i, G}}\right) \\
\overrightarrow{X_{i, G+1}}=\overrightarrow{X_{i, G}} & \text { if } f\left(\overrightarrow{U_{i, G}}\right)>f\left(\overrightarrow{X_{i, G}}\right)
\end{array}
$$

The Eq. implies that if the trial vector $\left(\overrightarrow{U_{i, G}}\right)$ has a lower or equal value of objective function $(f(\vec{X}))$ than target vector $\left(\overrightarrow{X_{i, G}}\right)$, the trial vector replace the corresponding target vector for the next generation. Both, The Tabu list concept (TL) and Taboo Search (TS) previously proposed by Glover ${ }^{67}$ allows to avoid revisit the search space by keeping a record of visited points. TL is randomly initialized at initial population and continuously updated with the newly generated trial individuals. This taboo check is carried out in the generation step to the trial vector, and the new trial individual is generated repeatedly until it is not near to any individual in the TL. The total trial individuals NP are generated by the repetition of above steps. The newly generated NP trial vectors are combined with the parent population to form a combined population with total 2NP individuals.

During the optimization, a vector of decision variables (this vector can be the trial or target vector) is sent from Excel $^{\mathrm{TM}}$ to Aspen Plus ${ }^{\mathrm{TM}}$ using Dynamic Data Exchange (DDE) through COM technology. Those values are used by Aspen Plus ${ }^{\mathrm{TM}}$ to simulate the process and obtain data as: flow streams, purities, reboiler heat duty, etc., and these data are used for evaluate the objective function. After simulation, Aspen Plus returns to Microsoft Excel a resulting vector that contains the output data generated by Aspen. In the case that an Aspen simulation generated with trial vector values not converge the trial vector is automatically discarded. Then, Microsoft Excel analyzes the objective function values and new vectors of decision variables are generated according to DETL method previously explained. The values of the required parameters to the DETL algorithm are the following: number of population (NP): 120 individuals, Generations Number (GenMax): 710, Tabu List size: 60 individuals, Tabu Radius: 0.01 , Crossover fractions $(\mathrm{Cr})$ : 0.8 , Mutation fractions $(\mathrm{F})$ : 0.3 . These values were taken from Srinivas and Rangaiah. ${ }^{63,66}$

\section{Results and discussion}

This section presents the main results of the design and simultaneous optimization considering the economic, environmental, and safety criteria. The results obtained satisfy the constraints related to the purity $(99.2 \% \mathrm{wt}$ for furfural and $99.5 \% \mathrm{wt}$ for methanol), whereas the mass flow rate was set to $6200 \mathrm{~kg} / \mathrm{h}$ for furfural and $2000 \mathrm{~kg} / \mathrm{h}$ for methanol. All sequences were optimized using RADFRAC ${ }^{\mathrm{TM}}$ module which is a rigorous model included in Aspen Plus ${ }^{\mathrm{TM}}$. All optimizations were carried out on a computer with AMD Ryzen ${ }^{\mathrm{TM}} 5-1600 @ 3.2 \mathrm{GHz}$, and 16GB of RAM. The computing time for obtaining the optimal pareto solutions is different for each process separation according to the complexity: QOP required $278 \mathrm{~h}$, TCC required $336 \mathrm{~h}$, TEC required 328 , DWCC required $350 \mathrm{~h}$ and $\mathrm{HIC}$ required $345 \mathrm{~h}$.

The Pareto front charts are used to analyse in a simpler way the obtained results. The objective of this section is to identify the best option to purify furfural through the analysis of Pareto fronts and performance indexes of the 
processes. The points of the Pareto fronts correspond to the 120 individuals for the generation 710 (last generation). After this generation there are no more improvements in the objective functions, which means that the results obtained are the optimal solutions. In the Figures S1- S3 of supplementary material is showed the evolution of Pareto front through the generations for TEC process as a representative case, in order to demonstrate that the objective functions cannot be further improved. For simplify the analysis and the explanations of the results for a better understating the Pareto fronts are shown in two dimensions.

7 Figure 7 shows the Pareto chart for the eco-indicator vs total annual cost. Each point in the plot represents a design for a respective process separation scheme. The designs to the right side of the graph are characterized by more stages, larger diameters, and higher energy usage. The form of the Pareto front indicates that the ecoindicator is strongly influenced by the steam used to supply the energy in the processes, and the electricity necessary to pump the cooling water, whereas the steel used for equipment exerts less influence. Previous works - as the one reported by Sanchez-Ramirez et al.$^{65}$ - have demonstrated that when steel has a strong influence in the eco-indicator, the relationship between TAC and EI99 corresponds to competing objectives. As can be noticed, there are several designs for all intensified schemes that have significant improvements in TAC and EI99 with the exception of heat integrated process (HIC) that has greater eco-indicator values than the benchmark configuration (Quaker Oats process). This increment in EI99 index is due to the extra equipment, such as the exchangers E1, E2 and the compressor required to integrate the heat between different streams.

Figure 8 shows the Pareto front of IR vs TAC. These indexes have a behaviour of antagonist objectives, which means that it is not possible to obtain a design with the lowest TAC and IR at the same time, hence when an index improves the other one gets worse. The individual risk depends mainly on two things, the first one is the physical properties of the substances to be separated - e.g. toxicity (LC50), flammability limits (LFL and UFL) and heat combustion - while the second one is the amount of each component inside the columns. Analysing the substances in the mixture to be separated and the topology of the separation schemes it is evident that water is the component in largest amount ( $90 \%$ wt in the mixture) and it is removed in the first column (C1), indicating that this equipment will have the largest size (with respect to other columns) and more inventory (mass inside the columns) and thus has more contribution to the safety index. If the reflux and reboiler duty are large in $\mathrm{C} 1$, there is an increase of water amount in the column yielding to a dilution of the organic components in this equipment and thus improving the safety index (decreasing the risk). However, larges reflux ratios and reboiler duties involve an increment on TAC caused by the increased use of utilities (steam and electricity). A similar behaviour occurs in the columns C2 and C3. Considering these arguments, it should be noted that the behaviour showed here between the individual risk and the total annual cost cannot be generalized to all mixtures.

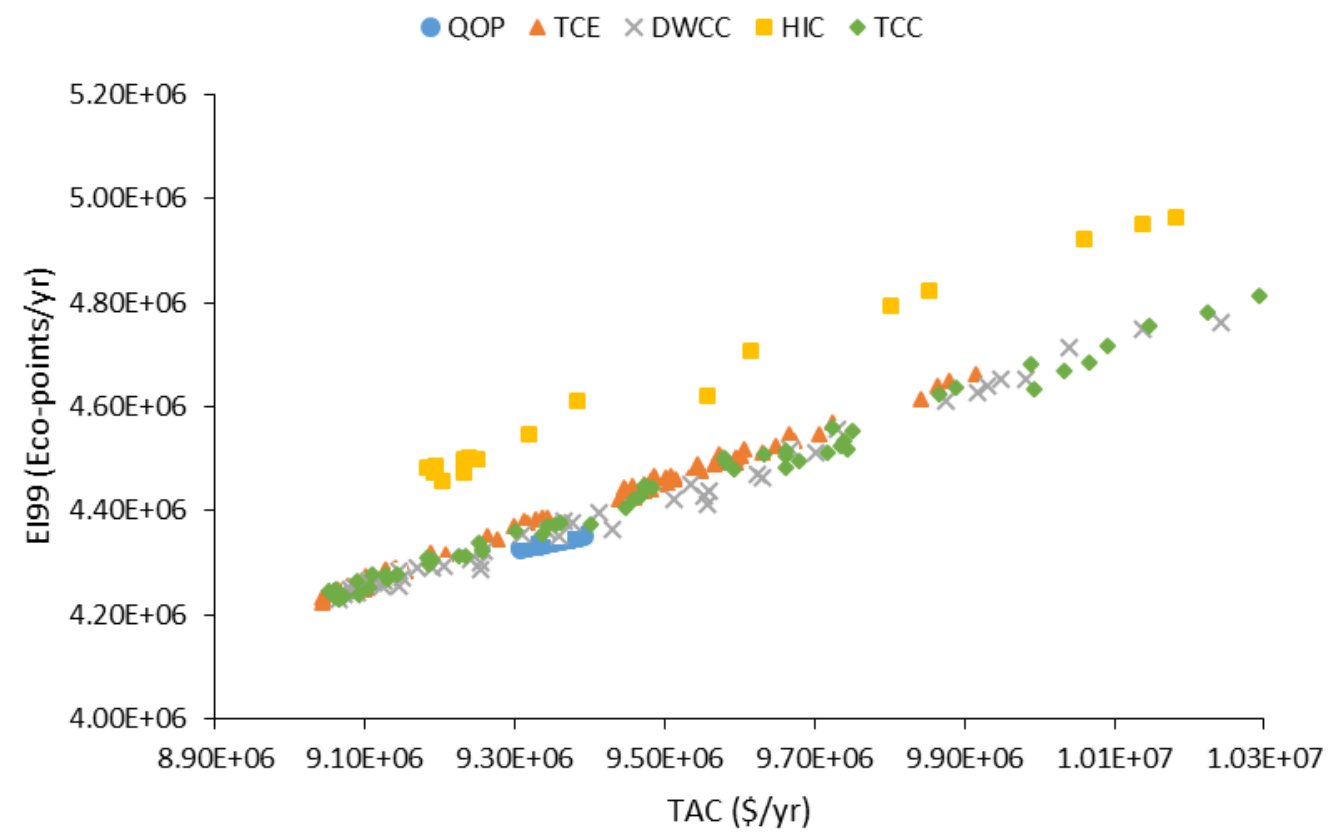


$1 \quad$ Figure 7: Pareto front between Eco-indicator 99 and Total Annual Cost

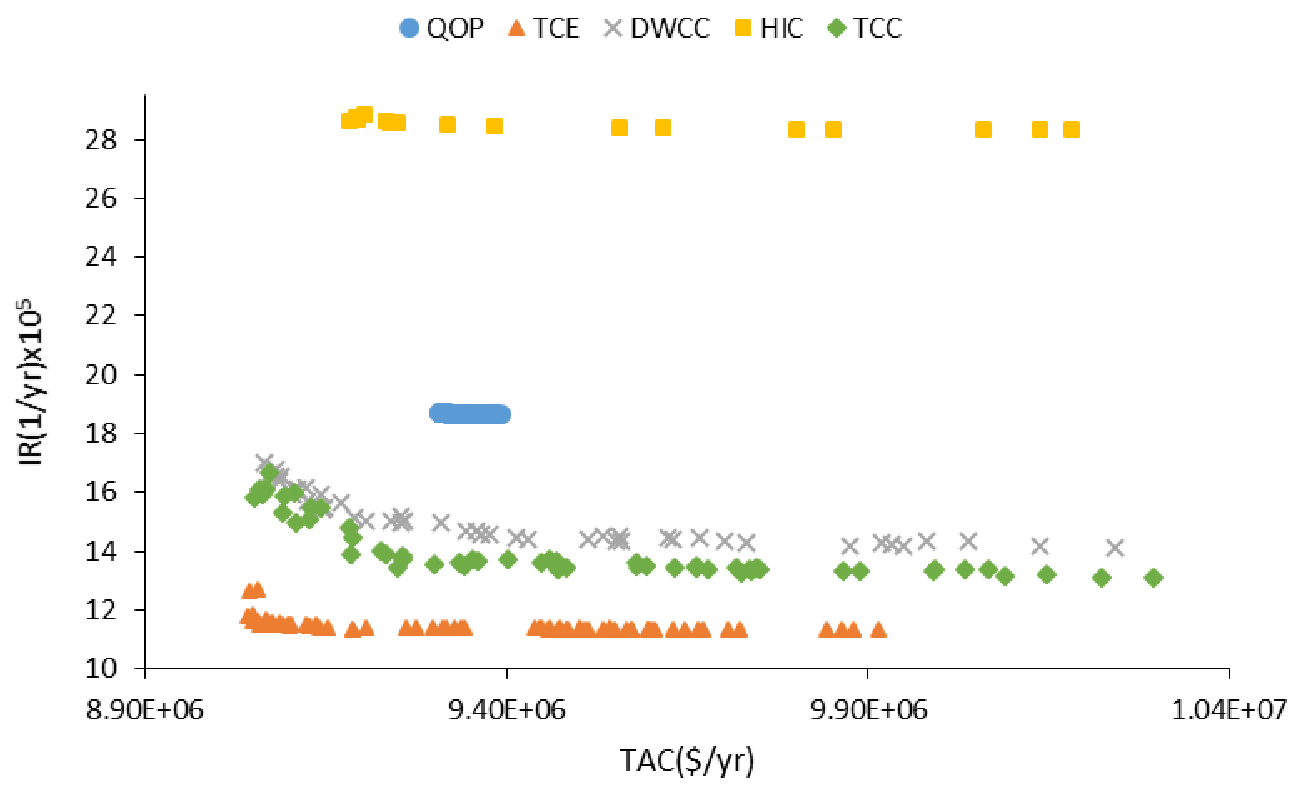

2

3 Figure 8: Pareto front between Individual Risk and Total Annual Cost

4

5

6

7

8

9

10

11

12

Figure 9 shows the Pareto front of the eco-indicator and individual risk. EI99 has the same tendency as TAC, so a similar behaviour should be expected for both indexes. Here, major reflux ratios and reboiler duty, imply higher use of steam and electricity, which impacts the eco-indicator. Due to the tendencies analyzed previously, it is clear that the designs chosen from the Pareto fronts should be those that have the best equilibrium between IR vs TAC and IR vs EI99. Because the eco-indicator and the total annual cost have the same tendency (see Figure 7), choosing a design that compensates the individual risk with TAC, for example, automatically selects the point with the best equilibrium between IR and EI99.

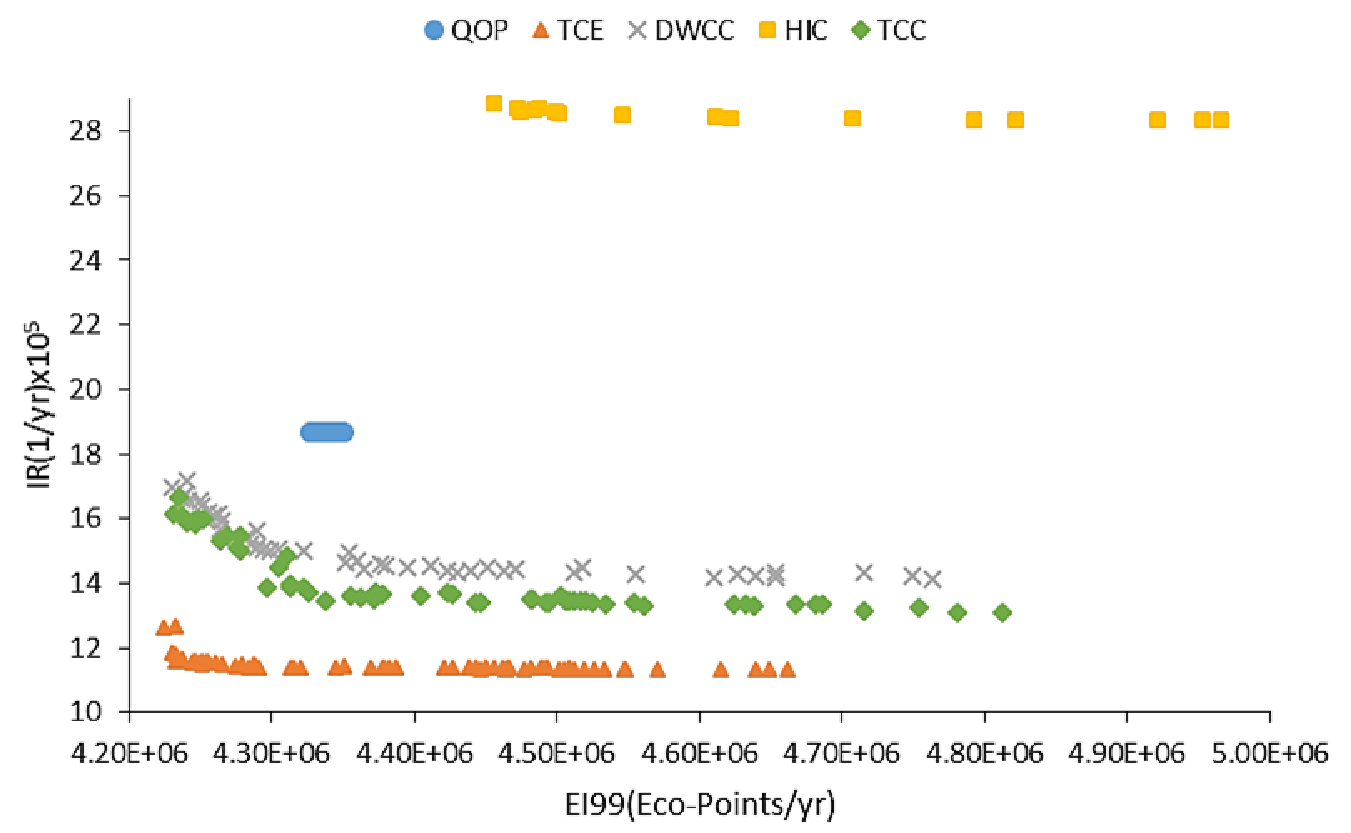


$1 \quad$ Figure 9: Pareto front between Individual Risk and Eco-Indicator 99

2 Figure 10, Figure 11, and Figure 12 show the Pareto charts of the thermodynamic equivalent sequence (TEC) as 3 a representative case. It is important to mention that all these sequences have the same behaviour for the Pareto 4 fronts. The black points in these figures correspond to the design chosen for TEC, while similar points were 5 selected for other separation sequences. The black triangles were selected according to the utopian point 6 methodology. The utopic point corresponds to a hypothetical and ideal solution in the border of the Pareto front 7 where two objectives cannot improve more and both are in equilibrium. The black triangles correspond to 8 solutions closer to utopic point according to reported by Wang and Rangaiah ${ }^{68}$. This methodology have been reported and implemented in several works by Contreras-Zarazua et al ${ }^{50}$, Sanchez-Ramirez et al ${ }^{65}$, QuirozRamirez et al. ${ }^{.57}$ and Medina-Herrera et $\mathrm{al}^{25}$. In order to demonstrate that the values of Pareto fronts are in the in the vicinity of the global optimum, the evolution of Pareto fronts through the generations for TEC sequences as a representative case is showed in the Figures S5-S7 of supplementary material.

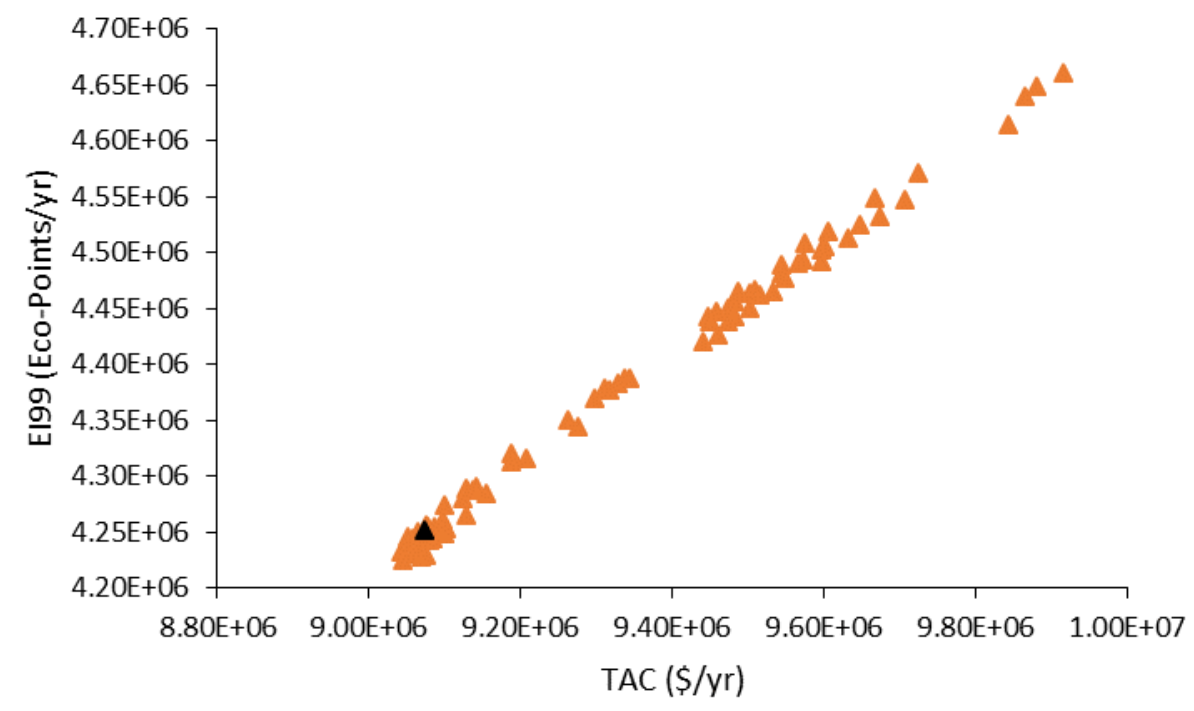

Figure 10: Pareto front between Eco-indicator 99 and Total Annual Cost for TEC scheme.

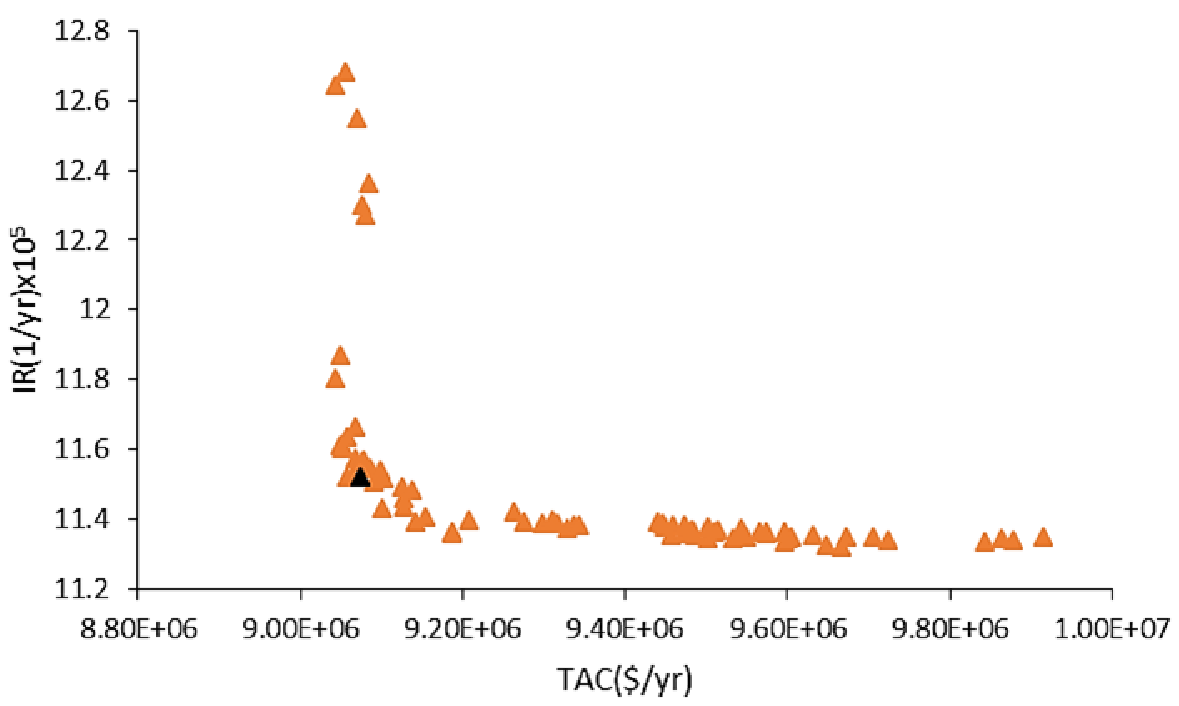

16 Figure 11: Pareto front between Individual Risk and Total Annual Cost for TEC scheme. 


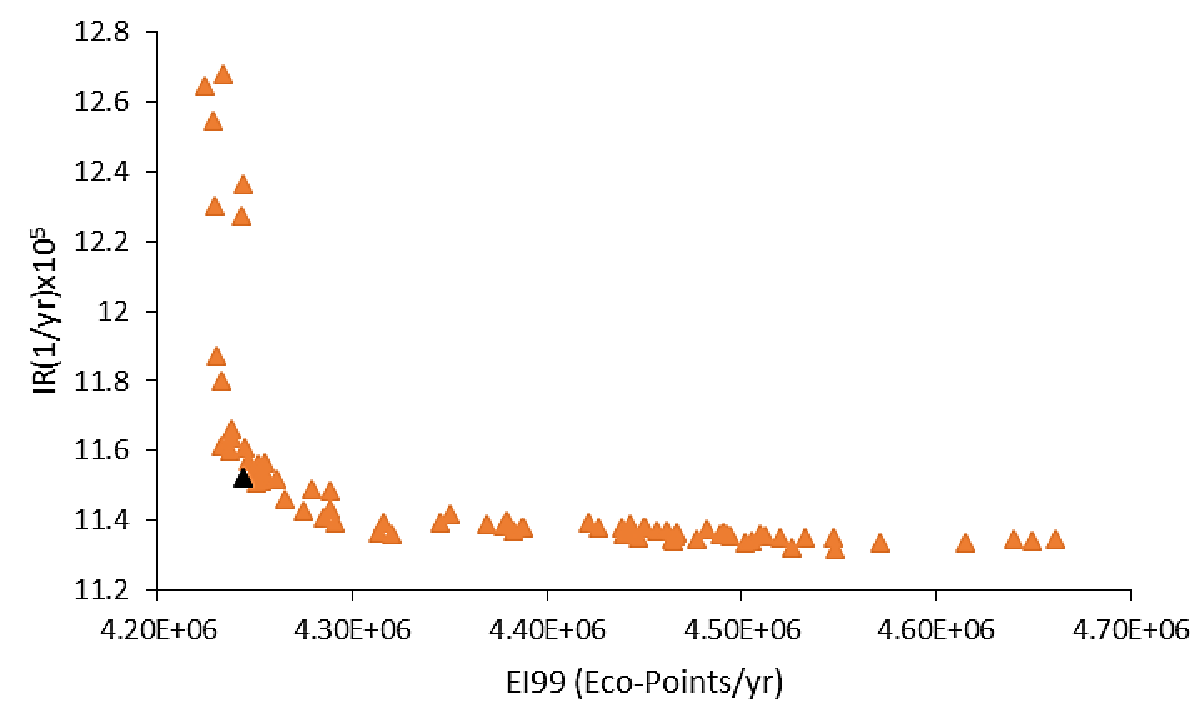

2 Figure 12: Pareto front between Individual Risk and Eco-Indicator 99for TEC scheme.

The optimal design parameters and values of the objective functions for all sequences are presented in Table 4 . As can be observed on Table 4, the column $\mathrm{C} 1$ is the largest piece of equipment from all schemes, which confirms the explanation previously mentioned: $\mathrm{C} 1$ is the column that contributes most to the three indexes. This column has the largest energy requirements and size - as it separates all water from the mixture, the energy required is very similar which leads to values of TAC and EI99 that are similar for all sequences. This can be demonstrated by observing the heat duty, the utilities cost and the temperature of the $\mathrm{C} 1$ bottom given in Table 4.

The reflux ratio on $\mathrm{C} 2$ and $\mathrm{C} 3$ are small in order to reduce the concentration of methanol and furfural through the columns and thus to decrease the risk of an accident. The QOP scheme and all alternatives (with the exception of DWCC) show a clear tendency to reduce the number of stages in C2 and C3 in order to abate the quantity of methanol and furfural in the columns.

Commonly, the researchers considered that dividing wall columns offer important improvements in safety due to these configurations using fewer units with respect to thermally coupled configurations. However, this work demonstrated that dividing wall columns do not always represent the best option with respect to safety. The DWC that resulted by the integration of columns $\mathrm{C} 1$ and $\mathrm{C} 2$ is shown Figure 4. The stages and the diameter of C2 that purifies methanol need to increase in order to integrate the two columns, which causes an increase of the concentration and amount of methanol on the side corresponding to $\mathrm{C} 2$, and affecting directly the individual risk index. This situation does not occur in thermally coupled systems. Although DWCC is not the best alternative in terms of safety, it is an improvement compared with the QOP alternative. This improvement is caused mainly by the elimination of one condenser, and having a more diluted concentration of the organic substances.

The TCC and TEC sequences are in theory thermodynamic equivalents of DWC. However, the topology of the scheme has an important role in safety. TCC and TEC have lower IR than DWCC as the size of the C2 column is smaller than in the DWC configuration, thus reducing the inventory. TEC has the best IR results showing a reduction of almost $40 \%$ of the inherent risk as compared with QOP. This reduction is due to the fact that methanol is purified in column $\mathrm{C} 1$ which is rich in water, thus reducing the methanol concentration and its toxic and flammability properties, while the $\mathrm{C} 2$ column does not purify methanol. The $\mathrm{C} 2$ column contains mainly water that is purified and sent to the decanter to promote the two liquid phase formation. The heat integrated configuration (HIC) shows the smallest energy consumption in column $\mathrm{C} 1$, however, the additional units (exchangers E1, E2 and compressor) offset the energy saving which is not reflected in TAC and EI99. In case of the individual risk, these additional units imply higher chances of a leak, affecting directly the safety index.

According to the results it is evident that the TEC is the best option to purify furfural, it has similar total annual cost and eco-indicator compared with the other alternatives. Nevertheless, the topology of TEC process provides 
a greater dilution on the organic substances which improves the safety of process. The Figure 13 shows a scheme of TEC process including all mass flows and energy requirements. Table 4 summarizes the optimal design parameters for all sequences considered. The best design were selected according to utopian point methodology. The utopic point corresponds to a hypothetical and ideal solution at the border of Pareto front where two objectives cannot improve more and both are in equilibrium. The optimal design (the black triangle in Pareto front) correspond to solutions closer to utopic point according to reported by Wang and Rangaiah ${ }^{68}$.

Even though all alternatives solve the MESH equations, both are also quite different. For example, the amount of matter involved in the thermally couplings of TCC is not necessary the same of the TEC. Moreover, the reflux ratio provide for section $\mathrm{V}$ in both cases is not the same, so evidently the MESH equations are not solved with the same parameter values. They are thermodynamic equivalent since perform a similar task with a similar amount of energy, but structurally are not equals. Regarding DWC, it is true that this alternative also carried out the same operation with similar energy, however, since the process unit possess a single shell the diameter values are not precisely the same.

An interesting work that shows a similar situation is the work of Hernández et al. ${ }^{69}$. They propose a set of ternary dividing wall columns, presented in the way of Petlyuk columns. All the alternatives were generating by moving sections. In brief they proposed a set six alternatives and the thermodynamic efficiency was further calculated. They results showed similar efficiencies, however, also it was clear the differences on the topology of all alternatives. Although this works does not proposes so many alternatives, the topologic differences of furfural alternatives may be understood under the light of the work of Hernandez et al. ${ }^{69}$.

On the other hand, the industrial application of Petlyuk column is the dividing wall column DWC. Note in Aspen Plus simulator, the DWC column must be simulated as a Petlyuk column, however, they are different since several physical/sizing consideration must be taken into account. A wider explanation of the industrial implementation is provided by Yildirim et al. ${ }^{70}$. Essentially, they perform the same task with the same amount of energy, in other words, they might be thermodynamically equivalent, however, they are structurally different. 


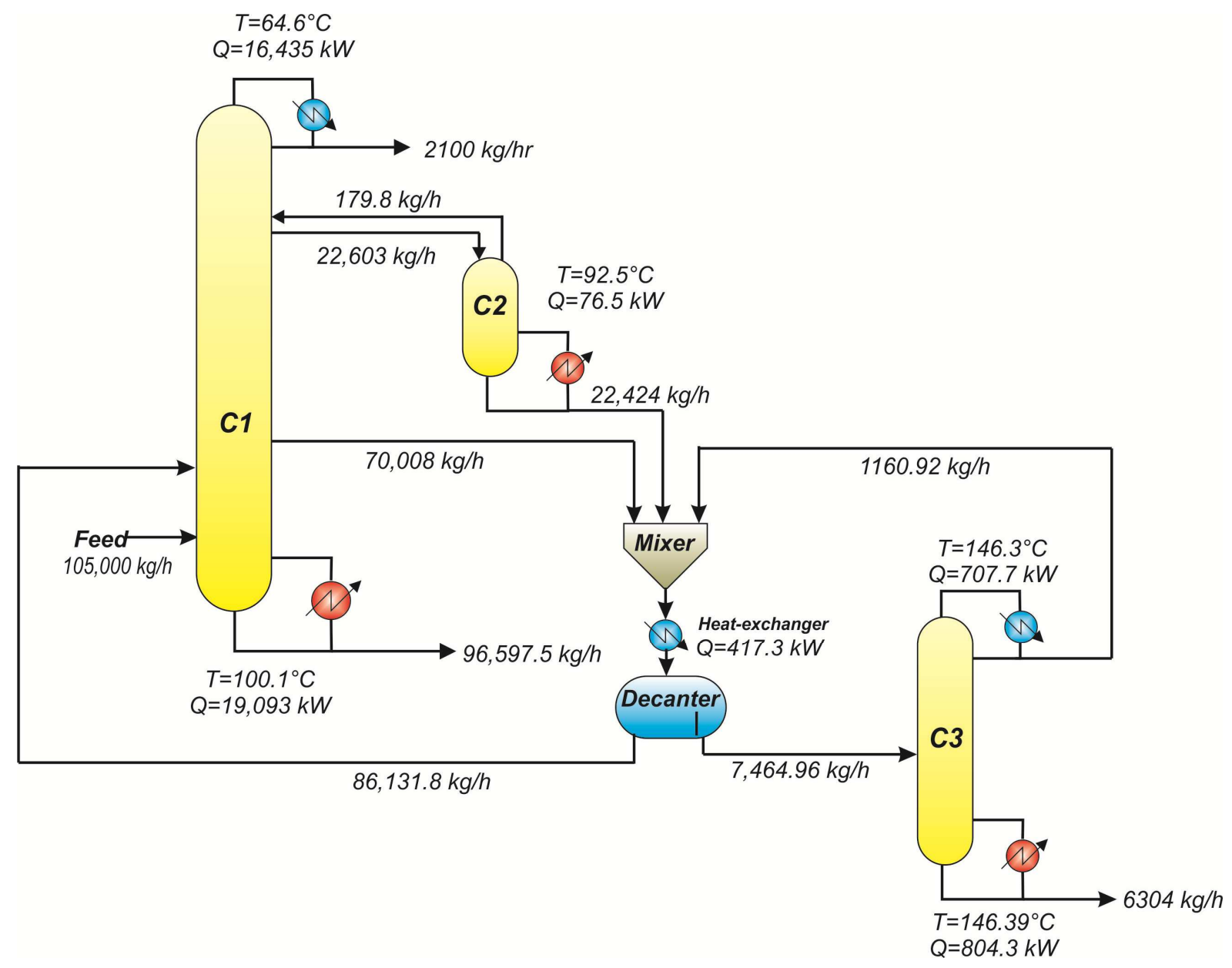

2 Figure 13: Mass flows and energy requirements for TEC process.

5 Table 4. Optimal design parameters for all separation sequences

\begin{tabular}{cccccc}
\hline Design Variables & QOP & TCC & TEC & DWCC & HIC \\
\hline Number of stages, C1 & 55 & 91 & 97 & 81 & 61 \\
Number of stages, C2 & 12 & 40 & 27 & 83 & 30 \\
Number of stages, C3 & 6 & 11 & 9 & 11 & 7 \\
Feed stage of water-rich phase C1 & 22 & 14 & 26 & 6 & 24 \\
Feed stage, C1 & 27 & 54 & 65 & 39 & 33 \\
Stage of side stream C1 & 16 & 39 & 43 & 33 & 12 \\
Feed stage C2 & 8 & 16 & 1 & - & 3 \\
Feed stage C3 & 3 & 6 & 3 & 4 & 0.71 \\
Diameter of C1, m & .44 & 1.1 & 1.02 & -57 & 0.90 \\
Diameter of C2, m & .42 & .95 & 0.36 & 2.57 & 1.4
\end{tabular}

\section{Operation Specifications}

Top pressure (atm)

1

1

1

1

1 


\begin{tabular}{|c|c|c|c|c|c|}
\hline Reflux ratio of $\mathrm{C} 1$ & 18.5 & - & 24.5 & - & 6.2 \\
\hline Reflux ratio of $\mathrm{C} 2$ & 0.21 & 25.24 & - & 25.14 & 0.83 \\
\hline Reflux ratio of C3 & 0.208 & 0.265 & 0.455 & 0.233 & 3.82 \\
\hline Heat duty of $\mathrm{C} 1(\mathrm{~kW})$ & 19096.8 & 19235 & 19093 & 19143 & 18659 \\
\hline Heat duty of C2(kW) & 770.17 & 117.1 & 76.5 & 191.2 & 1186.1 \\
\hline Heat duty of C3 (kW) & 456 & 1102 & 804.3 & 826.11 & 638 \\
\hline Energy of compressor $(\mathrm{kW})$ & - & - & - & 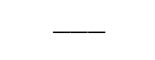 & 12 \\
\hline Total energy Consumed (kW) & 20322.97 & 20454 & 19973.32 & 20160.11 & 20495.19 \\
\hline $\begin{array}{c}\text { Discharge pressure of } \\
\text { compressor(Comp) (atm) }\end{array}$ & - & & & - & 1.265 \\
\hline Temperature bottom $\mathrm{C} 1\left({ }^{\circ} \mathrm{C}\right)$ & 100.09 & 100.01 & 100.09 & 100.09 & 100.07 \\
\hline Temperature bottom $\mathrm{C} 2\left({ }^{\circ} \mathrm{C}\right)$ & 64.54 & 90.95 & 92.45 & 92.81 & 76.45 \\
\hline Temperature bottom $\mathrm{C} 3\left({ }^{\circ} \mathrm{C}\right)$ & 143.43 & 161.4 & 146.39 & 154.05 & 161.38 \\
\hline
\end{tabular}

Streams mass flow $\left(\left(\mathrm{kg} \mathrm{h}^{-1}\right)\right.$

$\begin{array}{cccccc}\text { Feed } & 105,000 & 105,000 & 105,000 & 105,000 & 105,000 \\ \text { Methanol stream } & 2097.02 & 2102.2 & 2101 & 2099 & 2107.1 \\ \text { Furfural stream } & 6308.37 & 6299.59 & 6304 & 6300.8 & 6263.2 \\ \text { Waste Water stream } & 96594.7 & 96599.6 & 96597.5 & 96602.2 & 96629 \\ \text { Side stream } & 23,293 & 23712.9 & 70008.4 & 22931.8 & 26580 \\ \text { Water-rich phase stream } & 17,483 & 51118.8 & 86131.8 & 48628.3 & 24183.4 \\ \text { Organic-rich phase stream } & 6584.2 & 8375.9 & 7464.96 & 7687.22 & 7591.3 \\ \text { Liquid Stream } & - & 3649.2 & 22603.8 & 4696 & - \\ \text { Vapour Stream } & - & 39456 & 179.8 & 38790.3 & -\end{array}$

\begin{tabular}{cccccc}
\multicolumn{7}{c}{ Purity of main components (mass fraction) } \\
Methanol & 0.9999 & 0.9999 & 0.9999 & 0.9999 & 0.9972 \\
Furfural & 0.9924 & 0.9999 & 0.9938 & 0.9970 & 0.9999
\end{tabular}

Performance index

Utilities cost (millon\$/yr)

Equipment cost (million\$)

9.103

9.0243

8.8155

8.8972

9.1464

TAC (\$/yr)

2.307

2.7712

2.5965

3.5795

2.3791

9.334

9.301

9.075

9.255

9.384

Eco99 (million Eco-points/yr)

4.335

4.3623

4.2555

4.2992

4.6118

IR $(1 / \mathrm{yr}) * 10^{5}$

$18.674 \quad 13.548$

11.516

12.302

28.450

\section{Conclusions}

The new downstream processing configurations (for furfural purification) proposed in this study are competitive against the Quaker Oats Process used as a benchmark. The schemes proposed in this work are azeotropic distillation systems and they correspond to the category of heterogeneous azeotropic distillations. These heterogeneous azeotropic schemes are formed with at least two columns. The heterogeneous azeotropic scheme can or cannot contain the use of entrainer depending of components in the mixture to be separated and their respective compositions. In this case, the water has the function of an entrainer due to it is present in high concentration in the mixture. According with previous works (Widagdo and Seider, 1996) an azeotropic distillation column (azeotropic column) is the equipment that concentrate the mixture up to azeotrope concentration. Then, the distillate or a side stream is condensate and sent to a decanter where one of the phases is refluxed to the column. The other phase in sent (organic phase in this case) to a second column where its 
purification is finalized. Finally the products in this two columns systems are recovered by the bottoms of the columns. All alternatives were optimized using a DETL algorithm and considered the total annual cost, ecoindicator 99 and individual risk as key performance indexes. The results show that TAC and EI99 remain constant for all sequences. This can be explained by the fact that column $\mathrm{C} 1$ - the unit that contributes most to these indexes - uses most of the total energy of the sequences for the separation of the bulk water present in the mixture (90\%wt). This makes it difficult to improve the energy usage, TAC, and EI99 in all cases considered. However, the optimization results show that the topology of the intensified separation schemes has an important role on the safety criteria which can be significantly improved by process intensification.

Compared to the QOP benchmark, the intensified thermally coupled sequences (TCC, TEC, and DWCC) exhibit major reductions (from $27 \%$ up to $40 \%$ ) of the inherent risk associated with the lower concentration and amount of organic substances inside the distillation columns. For example, as the TEC process separates methanol and water in the same column, this leads to a dilution of methanol in the water which reduces their toxicity and flammability. However, the heat integrated configuration has the worst values of the inherent risk (52\% higher IR) as this process implies the use of extra units and a compressor, which further increases the risks. Among all sequences, the intensified TEC alternative is overall the best option to purify furfural, being the significantly safer (about 40\% lower IR) and slightly cheaper and more eco-friendly as compared with the QOP benchmark.

As has been discussed, the topology of the alternatives of this work are different. Even though the energy requirements are similar (thermodynamic equivalents) their structure is different. With this in mind, it is understandable the differences associated to IR values. However, it is clear the necessity (as future work) to know the layout of the process for better understanding of the distance among columns of the same process, and the role of that distance on IR calculation.

\section{Acknowledgments}

A. A. Kiss gratefully acknowledges the Royal Society Wolfson Research Merit Award.

\section{Nomenclature}

$\begin{array}{ll}\text { IR } & \text { Individual Risk } \\ \text { TAC } & \text { Total Annual Cost } \\ \text { EI99 } & \text { Eco-indicator 99 } \\ \text { QOP } & \text { Quaker Oats Process } \\ \text { TCC } & \text { Thermally Coupled Configuration } \\ \text { TEC } & \text { Thermodynamic equivalent configuration } \\ \text { DWCC } & \text { Dividing-wall column configuration } \\ \text { HIC } & \text { Heat integrated configuration } \\ \text { C1 } & \text { Column 1 (Azeotropic Column) } \\ \text { C2 } & \text { Column 2 (Methanol recovery column) } \\ \text { C2 } & \text { Column 3 (Furfural recovery column) } \\ \omega & \text { weighting factor for damage } \\ c_{i} & \text { value of impact for category i } \\ a s & \text { amount of steam utilized by the process } \\ a s l & \text { amount of steel used to build the equipments } \\ a e & \text { amount of electricity utilized by the process } \\ f_{i} & \text { The occurrence frequency of incident i } \\ P_{x, y} & \text { Probability of injury or decease caused by the incident i } \\ \text { BLEVE } & \text { Boiling liquid expanding vapor explosion } \\ \text { UVCE } & \text { Unconfined vapour cloud explotion } \\ t_{e} E_{r} & \text { Thermal Radiation doses } \\ p^{\circ} & \text { Overpressure due to explosions } \\ Y & \text { Probit Variable } \\ e r f & \text { Error Function }\end{array}$




\begin{tabular}{|c|c|}
\hline LC50 & Lethal concentration \\
\hline LFL & Lower flammability limit \\
\hline UFL & Upper flammability limit \\
\hline$N T_{i}$ & Total number of stages of column $\mathrm{i}$ \\
\hline$F s_{i}$ & Feed stages for column i \\
\hline$R_{i}$ & reflux ratio of column i \\
\hline$V F$ & Interconnection vapor flow \\
\hline$L F$ & Interconnection liquid flow \\
\hline$D C_{i}$ & Diameter of column i \\
\hline$H D_{i}$ & reboiler duty for column i \\
\hline$k$ & Compressor capacity \\
\hline$C_{i, j}$ & $\mathrm{C}_{\mathrm{i}, \mathrm{j}}$ in the concentration of substance $\mathrm{j}$ in column $\mathrm{i}$ \\
\hline$y_{m}$ & Purity obtained during the simulation \\
\hline$w_{m}$ & Mass obtained during the simulation \\
\hline$u_{m}$ & Purity requeired \\
\hline$x_{m}$ & Mass flow requiered \\
\hline DETL & Differential evolution with tabu list \\
\hline $\mathrm{TS}$ & Tabu search \\
\hline $\mathrm{DE}$ & Differential evolution \\
\hline G & Number of Genaration \\
\hline $\overrightarrow{V_{i, G}}$ & Mutant vector \\
\hline $\overrightarrow{X_{r_{\mathrm{j}, G}^{i}}}$ & Randomly vectors from the generation $G$ \\
\hline $\overrightarrow{U_{i, G}}$ & Trial vector \\
\hline$u_{j, i, G}$ & Elements of the trial vector \\
\hline$X_{i, G+1}$ & Parent vector of generation $\mathrm{G}+1$ \\
\hline NP & umber of population \\
\hline GenMax & Maximum generation number \\
\hline $\mathrm{Cr}$ & Crossover fraction \\
\hline $\mathrm{F}$ & Mutation factor \\
\hline
\end{tabular}

\section{References}

1. Steinbach, D., Kruse, A., Sauer, J.; Pretreatment technologies of lignocellulosic biomass in water in view of furfural and 5-hydroxymethylfurfural production - A review. Biomass Conversion and Biorefinery, 2017, $7(2), 247-274$.

2. U.S. Department of Energy; Top value added chemicals from biomass volume I-Results of screening for potential candidates from sugars and synthesis gas, (https://www.nrel.gov/docs/fy04osti/35523.pdf), Last visited on August 2004.

3. Cai, C. M., Zhang, T., Kumar, R., Wyman, C. E.; Integrated furfural production as a renewable fuel and chemical platform from lignocellulosic biomass. Journal of Chemical Technology and Biotechnology, 2014, 89(1), 2-10.

4. Drobs A. B., Larue O., Reimond A., De Campo E., Pera-Titus M.; Hexamethylenediamine (HDMA) from fossil- vs. bio-based routes: an economic and life cycle assessment comparative study. Green Chemistry, 2015, 17, 4760-4772.

5. Brown L. H., Watson D. D.; Phenol-furfural resins. Industrial and Engineering Chemistry, 1959, 51(5), 683-684.

6. Bhogeswararao S., Srinivas D.; Catalytic conversion of furfural to industrial chemicals over supported Pt and Pd catalysts. Journal of Catalysis, 2015, 327, 65-77. 
7. Zeitsch K. J.; The chemistry and technology of furfural and its many by-products. Amsterdam, Elsevier Science, 2000.

8. Sun L., Wang Q., Li L., Zhai J., Liu Y.; Design and control of extractive dividing wall column for separating benzene/cyclohexane mixtures. Industrial \& Engineering Chemistry Research, 2014, 53, 81208131.

9. Cordeiro G. M., de Figueiredo M. F., Ramos W. B., Sales F. A., Brito K. B., Brito R. P.; Systematic strategy for ob taining a divided-wall column applied to an extractive distillation process. Industrial \& Engineering Chemistry Research, 2017, 56, 4083-4094.

10. Nhien L. C., Van Duc Long N., Lee M.; Process design of hybrid extraction and distillation processes through a systematic solvent selection for furfural production. Energy Procedia, 2017, 105, 1084-1089.

11. Di Blasi C., Branca C., Galgano A.; Biomass screening for the production of furfural via thermal decomposition. Industrial \& Engineering Chemistry Research, 2010, 49, 2658-2671.

12. Mesa L., Morales M., Gonzales E., Cara C., Romero I., Castro E., Mussatto S. I.; Restructuring the process for furfural and xylose production from sugarcane bagasse in a biorefinery concept for ethanol production. Chemical Engineering and Processing: Process Intensification, 2014, 85, 196-202.

13. De Jong W., Marcotullio G.; Overview of biorefineries based on co-production of furfural, existing concepts and novel developments. International Journal of Chemical Reactor Engineering, 2010, 8(1), Article A69.

14. Martín, M., \& Grossmann, I. E. Optimal production of furfural and DMF from algae and switchgrass. Industrial \& Engineering Chemistry Research, 2015, 55(12), 3192-3202.

15. Liu, L., Chang, H. M., Jameel, H., \& Park, S. Furfural production from biomass pretreatment hydrolysate using vapor-releasing reactor system. Bioresource technology, 2018, 252, 165-171.

16. Errico M., Ramirez-Marquez C., Torres-Ortega C. E., Rong B.-G., Segovia-Hernandez J. G.; Design and control of an alternative distillation sequence for bioethanol purification. Journal of Chemical Technology and Biotechnology, 2015, 90(12), 2180-2185.

17. Luo H., Bildea C. S., Kiss A. A.; Novel heat-pump-assisted extractive distillation for bioethanol purification, Industrial \& Engineering Chemistry Research, 2015, 54, 2208-2213.

18. Patrascu I., Bildea C. S., Kiss A. A., Eco-efficient downstream processing of biobutanol by enhanced process intensification and integration, ACS Sustainable Chemistry \& Engineering, 2018, 6, 5452-5461.

19. Errico M., Sanchez-Ramirez E., Quiroz-Ramìrez J. J., Rong B.-G., Segovia-Hernandez J. G.; Multi objective optimal acetone-butanol-ethanol (ABE) separation systems using liquid-liquid extraction assisted divided wall columns. Industrial \& Engineering Chemistry Research, 2017, 56, 11575-11583.

20. Kiss A. A.; Advanced distillation technologies - Design, control and applications, Wiley, Hoboken, US, 2013.

21. Kiss A. A.; Distillation technology - Still young and full of breakthrough opportunities, Journal of Chemical Technology and Biotechnology, 2014, 89, 479-498.

22. Qian X., Jia S., Skogestad S., Yuan X.; Design and control of azeotropic dividing wall column for separating furfural-water mixture. Computer Aided Chemical Engineering, 2016, 38, 409-414.

23. Ghosh U. K., Pradhan N. C., Adhikari B.; Pervaporative separation of furfural from aqueous solution using modified polyurethaneurea membrane. Desalination, 2010, 252, 1-7.

24. Medina-Herrera, N., Jiménez-Gutiérrez, A., \& Mannan, M. S.; Development of inherently safer distillation systems. Journal of Loss Prevention in the Process Industries, 2014, 29, 225-239.

25. Medina-Herrera, N., Grossmann, I. E., Mannan, M. S., Jiménez-Gutiérrez, A.; An approach for solvent selection in extractive distillation systems including safety considerations. Industrial \& Engineering Chemistry Research, 2014, 53(30), 12023-12031.

26. Martinez-Gomez, J., Sánchez-Ramírez, E., Quiroz-Ramírez, J. J., Segovia-Hernandez, J. G., Ponce-Ortega, J. M., El-Halwagi, M. M.; Involving economic, environmental and safety issues in the optimal purification of biobutanol. Process Safety and Environmental Protection, 2016, 103, 365-376. 
27. Martinez-Gomez, J., Ramírez-Márquez, C., Alcántara-Ávila, J. R., Segovia-Hernández, J. G., PonceOrtega, J. M.; Intensification for the silane production involving economic and safety objectives. Industrial \& Engineering Chemistry Research, 2016, 56(1), 261-269.

28. Nhien L. C., Van Duc Long N., Kim S., Lee M.; Design and optimization of intensified biorefinery process for furfural production through a systematic procedure. Biochemical Engineering Journal, 2016, 116, 166175.

29. Marcotullio, Gianluca. "The chemistry and technology of furfural production in modern lignocellulosefeedstock biorefineries." 2011.

30. Errico M., Sanchez-Ramirez E., Quiroz-Ramírez J. J., Segovia-Hernandez J. G., Rong B.-G.; Synthesis and design of new hybrid configurations for biobutanol purification. Computers \& Chemical Engineering, 2016, $84,482-492$.

31. Errico, M., \& Rong, B. G. (2012). Synthesis of new separation processes for bioethanol production by extractive distillation. Separation and purification technology, 2012, 96, 58-67.

32. Steingaszner P., Balint A, Kojnok M.; Improvement of a furfural distillation plant. Periodica Polytechnica Chemical Engineering, 1977, 21(1), 59-71.

33. Rong B.-G., Kraslawski A., Nystrom L.; The synthesis of thermally coupled distillation flowsheets for separations of five-component mixtures. Computers and Chemical Engineering, 2000, 24, 247-252.

34. Calzon-McConville C.J., Rosales-Zamora Ma.B., Segovia-Hernandez J.G., Hernandez S., Rico-Ramirez V.; Design and optimization of thermally coupled distillation schemes for the separation of multicomponent mixtures. Industrial \& Engineering Chemistry Research, 2006, 45, 724-732.

35. Errico M., Rong B.-G., Tola G., Turunen I.; Process intensification for the retrofit of a multicomponent distillation plant - An industrial case study. Industrial \& Engineering Chemistry Research, 2008, 47, 19751980.

36. Hohmann, E. G., Sander, M. T., \& Dunford, H. 1982. A new approach to the synthesis of multicomponent separation schemes. Chem. Eng. Commun., 1982, 17(1-6), 273-284.

37. Segovia-Hernández, J. G., Hernández, S., Rico-Ramırez, V., \& Jiménez, A. A comparison of the feedback control behavior between thermally coupled and conventional distillation schemes. Computers \& chemical engineering, 2004, 28(5), 811-819.

38. Segovia-Hernández, J. G., Hernández-Vargas, E. A., \& Márquez-Munoz, J. A. Control properties of thermally coupled distillation sequences for different operating conditions. Computers \& chemical engineering, 2007, 31(7), 867-87.

39. Dejanović I., Matijašević Lj., Olujić Ž.; Dividing wall column - A breakthrough towards sustainable distilling. Chemical Engineering and Processing: Process Intensification, 2010, 49(6), 559-580.

40. Gómez-Castro F. I., Segovia-Hernández J. G., Hernández S., Gutiérrez-Antonio C., Briones-Ramírez A.; Dividing wall distillation columns: Optimization and control properties. Chemical Engineering \& Technology, 2008, 31(9), 1246-1260.

41. Kiss A. A., Novel applications of dividing-wall column technology to biofuel production processes, Journal of Chemical Technology and Biotechnology, 2013, 88, 1387-1404.

42. Patrascu I., Bildea C. S., Kiss A. A., Dynamics and control of a heat pump assisted extractive dividing-wall column for bioethanol dehydration, Chemical Engineering Research and Design, 2017, 119, 66-74.

43. Errico M., Sanchez-Ramirez E., Quiroz-Ramirez J. J., Rong B.-G., Segovia-Hernandez J. G.; Biobutanol purification by hybrid extraction-divided wall column configurations. Computer Aided Chemical Engineering, 2017, 40, 1027-1032.

44. Errico M., Rong B.-G., Tola G., Spano M.; Optimal synthesis of distillation systems for bioethanol separation. Part 2: Extractive distillation with complex columns. Industrial \& Engineering Chemistry Research, 2013, 52, 1620-1626.

45. Rathore R. N. S., van Wormer K. A., Powers G. J.; Synthesis strategies for multicomponent separation systems with energy integration. AIChE Journal, 1974, 20(3), 491-502. 
46. Alcántara-Avila, J. R., Gómez-Castro, F. I., Segovia-Hernández, J. G., Sotowa, K. I., \& Horikawa, T. Optimal design of cryogenic distillation columns with side heat pumps for the propylene/propane separation. Chemical Engineering and Processing: Process Intensification, 2014, 82, 112-122.

47. Shi, L., Huang, K., Wang, S. J., Yu, J., Yuan, Y., Chen, H., \& Wong, D. S. (2015). Application of vapor recompression to heterogeneous azeotropic dividing-wall distillation columns. Industrial \& Engineering Chemistry Research, 2015, 54(46), 11592-11609.

48. Jana, Amiya K.; MAITI, Debadrita. Assessment of the implementation of vapor recompression technique in batch distillation. Separation and Purification Technology, 2013, vol. 107, p. 1-10.

49. Luo, Hao, Costin Sorin Bildea, and Anton A. Kiss. "Novel heat-pump-assisted extractive distillation for bioethanol purification." Industrial \& Engineering Chemistry Research 54.7 2015, 2208-2213.

50. Contreras-Zarazúa, Gabriel, et al. "Multi-objective optimization involving cost and control properties in reactive distillation processes to produce diphenyl carbonate." Computers \& Chemical Engineering. 105 2017, 185-196.

51. Zhang, Qingjun, Meiling Liu, and Aiwu Zeng. "Performance enhancement of pressure-swing distillation process by the combined use of vapor recompression and thermal integration." Computers \& Chemical Engineering 2018.

52. Guthrie, K. M.; Capital cost estimation. Chemical Engineering, 1969, 24, 114-142.

53. Turton, R., Bailie, R. C., Whiting, W. B., Shaeiwitz, J. A., Bhattacharyya D.; Analysis, synthesis and design of chemical processes. Prentice Hall, 4th edition, 2012.

54. Goedkoop, M.; Spriensma, R.; The eco-indicator 99. A damage oriented method for life cycle impact assessment; Methodology report nr. 1999/36A; Pré product ecology consultants, 2001.

55. Guillen-Gosalbez, G., Caballero, J. A., Jimenez, L.; Application of life cycle assessment to the structural optimization of process flowsheets, Industrial \& Engineering Chemistry Research, 2008, 47(3), 777-789.

56. Alexander, B., Barton, G., Petrie, J., Romagnoli, J.; Process synthesis and optimisation tools for environmental design: methodology and structure. Computers \& Chemical Engineering, 2000, 24(2-7), 1195-1200.

57. Quiroz-Ramírez, J. J., Sánchez-Ramírez, E., Hernández-Castro, S., Segovia-Hernández, J. G., PonceOrtega, J. M.; Optimal planning of feedstock for butanol production considering economic and environmental aspects, ACS Sustainable Chemistry \& Engineering, 2017, 5(5), 4018-4030.

58. Mettier, T.; Der Vergleich von Schutzgütern-Ausgewählte Resultate einer Panelbefragung. tze zum Vergleich von Umweltsch; ETH Zurich, Switzerland, 1999.

59. American Institute of Chemical Engineers. Guidelines for chemical process quantitative risk analysis; John Wiley \& Sons: New York, NY, USA, 2000.

60. Crowl, Daniel A.; Louvar, Joseph F. Chemical process safety: fundamentals with applications. Pearson Education, 2001.

61. National Institute for Occupational Safety and Health (NIOSH), https://www.cdc.gov/niosh/index.htm.

62. Górak, Andrzej, and Zarko Olujic, eds. Distillation: equipment and processes. Academic Press, 2014.

63. Rangaiah, G. P.; Stochastic global optimization: Techniques and applications in chemical engineering. World Scientific, 2010.

64. Storn, R., Price, K.; Differential evolution-a simple and efficient heuristic for global optimization over continuous spaces. Journal of Global Optimization, 1997, 11(4), 341-359.

65. Sánchez-Ramírez, E., Quiroz-Ramírez, J. J., Segovia-Hernández, J. G., Hernández, S., Ponce-Ortega, J. M.; Economic and environmental optimization of the biobutanol purification process. Clean Technologies and Environmental Policy, 2016, 18(2), 395-411.

66. Srinivas M., Rangaiah G. P.; Differential evolution with TL for solving nonlinear and mixed-integer nonlinear programming problems, Industrial \& Engineering Chemistry Research, 2007, 46, 7126-7135.

67. Glover, F. 1989. Tabu search—part I. ORSA Journal on computing, 1(3), 190-206. 
68. Wang, Z., Rangaiah, G. P. Application and analysis of methods for selecting an optimal solution from the Pareto-optimal front obtained by multiobjective optimization. Industrial \& Engineering Chemistry Research, 2017, 56(2), 560-574.

69. Hernández, S., Segovia-Hernández, J. G., \& Rico-Ramírez, V. Thermodynamically equivalent distillation schemes to the Petlyuk column for ternary mixtures. Energy, 2006, 31(12), 2176-2183.

70. Yildirim, Ö., Kiss, A. A., \& Kenig, E. Y. Dividing wall columns in chemical process industry: a review on current activities. Separation and Purification Technology, 2011, 80(3), 403-417.

71. Widagdo, S., Seider, W.D., 1996, Azeotropic Distillation, AIChEJ, 42, 96-130. 